\title{
Removal of heavy metal ions from wastewater: a comprehensive and critical review
}

\author{
Naef A. A. Qasem (iD) ${ }^{1,2 凶}$, Ramy H. Mohammed iD $^{3}$ and Dahiru U. Lawal $\mathbb{D}^{2}$
}

Removal of heavy metal ions from wastewater is of prime importance for a clean environment and human health. Different reported methods were devoted to heavy metal ions removal from various wastewater sources. These methods could be classified into adsorption-, membrane-, chemical-, electric-, and photocatalytic-based treatments. This paper comprehensively and critically reviews and discusses these methods in terms of used agents/adsorbents, removal efficiency, operating conditions, and the pros and cons of each method. Besides, the key findings of the previous studies reported in the literature are summarized. Generally, it is noticed that most of the recent studies have focused on adsorption techniques. The major obstacles of the adsorption methods are the ability to remove different ion types concurrently, high retention time, and cycling stability of adsorbents. Even though the chemical and membrane methods are practical, the large-volume sludge formation and post-treatment requirements are vital issues that need to be solved for chemical techniques. Fouling and scaling inhibition could lead to further improvement in membrane separation. However, pre-treatment and periodic cleaning of membranes incur additional costs. Electrical-based methods were also reported to be efficient; however, industrial-scale separation is needed in addition to tackling the issue of largevolume sludge formation. Electric- and photocatalytic-based methods are still less mature. More attention should be drawn to using real wastewaters rather than synthetic ones when investigating heavy metals removal. Future research studies should focus on ecofriendly, cost-effective, and sustainable materials and methods.

npj Clean Water (2021)4:36; https://doi.org/10.1038/s41545-021-00127-0

\section{INTRODUCTION}

The presence of heavy metals in wastewater has been increasing with the growth of industry and human activities, e.g., plating and electroplating industry, batteries, pesticides, mining industry, rayon industry, metal rinse processes, tanning industry, fluidized bed bioreactors, textile industry, metal smelting, petrochemicals, paper manufacturing, and electrolysis applications. The heavy metal contaminated wastewater finds its way into the environment, threatening human health and the ecosystem. The heavy metals are non-biodegradable ${ }^{1}$ and could be carcinogenic $^{2-6}$; thus, the presence of these metals in water by improper amounts could result in critical health issues to living organisms.

The most popular heavy metals are lead (Pb), zinc ( $\mathrm{Zn})$, mercury $(\mathrm{Hg})$, nickel (Ni), cadmium (Cd), copper (Cu), chromium (Cr), and arsenic (As). Although these heavy metals can be detected in traces; however, they are still hazardous. Table 1 summarizes some heavy metals, focusing on their major sources, health effects, and the permitted quantity in drinking water. The aforementioned metals and others such as silver ( $\mathrm{Ag})$, iron ( $\mathrm{Fe})$, manganese $(\mathrm{Mn})$, molybdenum (Mo), boron (B), calcium (Ca), antimony (Sb), cobalt (Co), etc. are commonly available in wastewater and need to be removed.

Recent studies have focused on a particular method for heavy metal ions removal, such as electrocoagulation (EC), adsorption using synthetic and natural adsorbents, magnetic field implementation, advanced oxidation processes, membranes, etc. These studies stood on the advantages and disadvantages of a specific method for wastewater treatment, including heavy metal removal. A complete picture of the heavy metals removal methods from wastewater resources has not been drawn yet. Therefore, the present review comprehensively and critically discusses the available technologies to expel heavy metal ions from wastewater efficiently. Moreover, it is essential to choose the most applicable method based on the removal efficiency, chemicals added/ adsorbents, initial concentration, optimal treated $\mathrm{pH}$ value, and other operating conditions.

The methods discussed in this review are classified into adsorption-, membrane-, chemical-, electric-, and photocatalyticbased treatments. An assessment for each method is conducted. Additional details about the operating conditions, removal efficiency, and important remarks of each method are listed for the reported studies in the literature in the accompanying Supplementary Information file. The literature research is selected based on the availability of the operating and performance parameters for each method.

\section{ADSORPTION-BASED SEPARATION}

The adsorption mechanism is defined by the physicochemical properties of adsorbent and heavy metals and operating conditions (i.e., temperature, adsorbent amount, $\mathrm{pH}$ value, adsorption time, and initial concentration of metal ions). Generally, heavy metal ions can be adsorbed onto the adsorbent's surface, as shown in Fig. 1a. This method was reported to have low operating costs, high removal capacity, easy implementation, and simple treatment by regenerating the adsorbed heavy metal ions ${ }^{7}$. Different types were developed for wastewater remediation, as discussed in the following sections.

\footnotetext{
${ }^{1}$ Department of Aerospace Engineering, King Fahd University of Petroleum \& Minerals (KFUPM), Dhahran, Saudi Arabia. ${ }^{2}$ Interdisciplinary Research Center for Membranes and Water Security, King Fahd University of Petroleum \& Minerals (KFUPM), Dhahran, Saudi Arabia. ${ }^{3}$ Department of Mechanical Power Engineering, Zagazig University, Zagazig, Egypt.

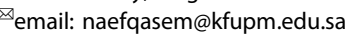


N.A.A. Qasem et al.

Table 1. Typical heavy metals existing in wastewater and their sources, in addition to the health issues caused by improper quantities and the permitted amounts in drinking water based on the world health organization (WHO) recommendations ${ }^{9}$.

\begin{tabular}{|c|c|c|c|}
\hline $\begin{array}{l}\text { Common } \\
\text { heavy metal }\end{array}$ & Main sources ${ }^{9,10,132}$ & Main organ and system affected ${ }^{11-15}$ & $\begin{array}{l}\text { Permitted } \\
\text { amounts }(\mu \mathrm{g})^{9}\end{array}$ \\
\hline Lead $(\mathrm{Pb})$ & $\begin{array}{l}\text { Lead-based batteries, solder, alloys, cable sheathing } \\
\text { pigments, rust inhibitors, ammunition, glazes, and } \\
\text { plastic stabilizers. }\end{array}$ & $\begin{array}{l}\text { Bones, liver, kidneys, brain, lungs, spleen, } \\
\text { immunological system, hematological system, } \\
\text { cardiovascular system, and reproductive system. }\end{array}$ & 10 \\
\hline Arsenic (As) & Electronics and glass production. & $\begin{array}{l}\text { Skin, lungs, brain, kidneys, metabolic system, } \\
\text { cardiovascular system, immunological system, and } \\
\text { endocrine. }\end{array}$ & 10 \\
\hline Zinc $(Z n)$ & $\begin{array}{l}\text { Brass coating, rubber products, some cosmetics, and } \\
\text { aerosol deodorants. }\end{array}$ & $\begin{array}{l}\text { Stomach cramps, skin irritations, vomiting, nausea, } \\
\text { and anemia, and convulsions. }\end{array}$ & 3000 \\
\hline Chromium $(\mathrm{Cr})$ & Steel and pulp mills and tanneries. & $\begin{array}{l}\text { Skin, lungs, kidneys, liver, brain, pancreas, tastes, } \\
\text { gastrointestinal system, and reproductive system }\end{array}$ & 50 \\
\hline Nickel (Ni) & Stainless steel and nickel alloy production. & $\begin{array}{l}\text { Lung, kidney, gastrointestinal distress, pulmonary } \\
\text { fibrosis, and skin. }\end{array}$ & 70 \\
\hline
\end{tabular}

(a)

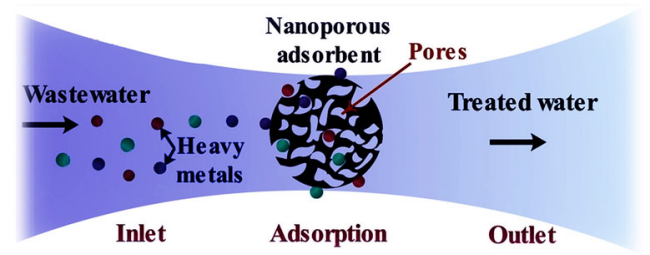

(b)

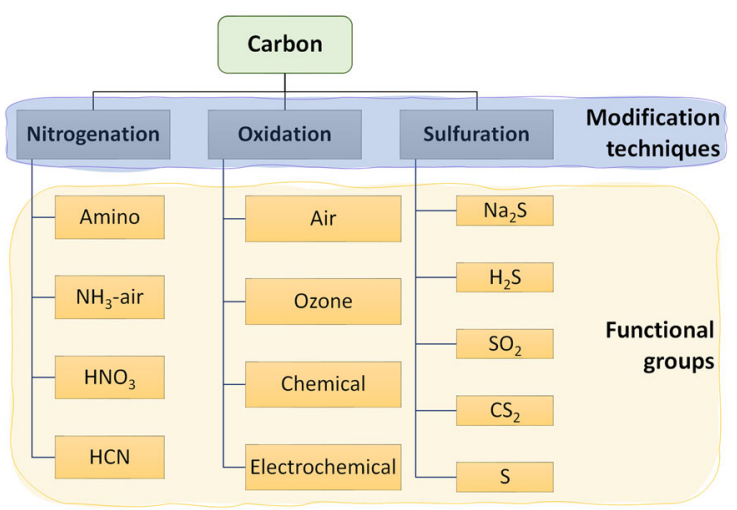

Fig. 1 Adsorption process used for water treatment. a Heavy metal ions adsorption process; the metal ions of wastewater adhere to the surface of nanoporous adsorbents, which has a high surface area due to its porosity. The adsorption process could be selective for one or more metals than others. The regeneration process could be achieved using a desorbing agent. b Various modification techniques (i.e., nitrogenation, oxidation, and sulfuration) are used to functionalize carbon with different functional groups. Functionalization enhances adsorption capacity and stability.

\section{Carbon-based adsorbents}

Carbon-based nanoporous adsorbents, especially activated carbons (ACs), carbon nanotubes (CNTs), and graphene (GN), are extensively used in the applications of heavy metal removal owing to their tremendous surface area $\left(500-1500 \mathrm{~m}^{2} / \mathrm{g}\right)^{8}$. The carbon surface charges can be enhanced by surface functional groups (such as carboxyl, phenyl, and lactone groups, as shown in Fig. 1b) to improve the heavy metal uptake ${ }^{9}$. Among various modification methods, nitrogenation, oxidation, and sulfuration are the most commonly employed techniques to enhance the specific surface area, pore structure, adsorption capacity, thermal stability, and mechanical strength ${ }^{10}$. However, they depend mainly on the adsorbent materials, which sometimes are very expensive ${ }^{11}$. Subsequently, adsorbent's cost should be considered in choosing the most suitable adsorbents.

Surface modification often reduces its surface area and, in turn, increases the content of surface functional groups. Consequently, more metal ions can be adsorbed ${ }^{12}$. Supplementary Tables 1 and 2 summarize the removal capacity and characteristics of carbonbased adsorbents and composite adsorbents. The adsorption uptake increases by increasing the adsorbent surface area, adsorbent dose, initial concentration of metal ions, and contact time. Although the multi-wall carbon nanotubes (MWCNTs) have received particular interest for heavy metal removal ${ }^{13}$, they are highly hydrophobic and suffer from rapid aggregation in aqueous solution due to large Van der Waals forces, decreasing the adsorption potential.

There is a lack of literature in quantitative assessment of functional groups' role in heavy metal ions sorption. Moreover, the current surface modification techniques demand high heat/ pressure, strong acid/base, or intensive oxidation/reduction reactions. This complex preparation process makes the carbonbased adsorbents expensive, burdening their widespread use in industrial applications. Thus, researchers should propose innovative, low-cost, and environmentally friendly surface modification techniques.

\section{Chitosan-based adsorbents}

Chitosan (CS) is a natural adsorptive polymer that has an affinity toward pollutants in wastewaters because it has amino $\left(-\mathrm{NH}_{2}\right)$ and hydroxyl $(-\mathrm{OH})$ groups $^{14}$. Despite its unique features, it suffers from low mechanical strength and poor stability ${ }^{15}$, making the regeneration inefficient. Also, it is challenging to use CS in its 
powder or flake form because of its low porosity, low surface area, resistance to mass transfer, and high crystallinity ${ }^{15}$. Consequently, structural and chemical modifications have been proposed to overcome these drawbacks. Cross-linking chemical modification imparts strength to CS by bridging between polymer chains and the functional groups. However, this approach reduces the uptake $^{16}$.

Grafting is another chemical modification method that involves the covalent bonding of functional groups (like amine and hydroxyl) on the backbone of CS, leading to a remarkable increase in the adsorption capacity ${ }^{17}$. Combining CS with other adsorbent materials has also been proposed to enhance CS's adsorption capacity, mechanical strength, and thermal stability ${ }^{18}$. The ionimprinting technique was followed to prepare adsorbents which high selectivity for target metal ions ${ }^{19}$.

Supplementary Table 3 lists the uptake of different CSs for heavy metal ions removal from wastewater. Generally, the uptake of CS depends mainly on the presence of protonation or non-protonation of amine $\left(-\mathrm{NH}_{2}\right)$ and phosphoric $\left(\mathrm{H}_{3} \mathrm{PO}_{4}\right)$ groups, which affect the $\mathrm{pH}$ value of the wastewater. In the absence of the modifications, CS-based shows low reusability. This behavior might be attributed to the strong bond (between the metal ions and adsorbent surface), low thermal/chemical stability, low mechanical strength, incomplete desorption, declination in the effective adsorbate-adsorbent interaction, and unavailability of adsorption sites ${ }^{20}$. So, alternative regeneration methods and modifications should be proposed to enhance the reusability of CSs.

\section{Mineral adsorbents}

Mineral adsorbents such as zeolite, silica, and clay are considered good candidates for water purification with low operating costs ${ }^{21}$. Clay has extraordinary cation exchange capacity (CEC), cation exchange selectivity, surface hydrophilicity, high swelling/expanding capacity, and surface electronegativity ${ }^{22}$. In addition, acid washing, thermal treatment, and pillar bearing could enlarge the pore size, pore volume, and specific surface area, leading to a remarkable increase in the adsorption efficiency ${ }^{22}$. Research studies (listed in Supplementary Table 4) showed that physical adsorption, chemical adsorption, and ion exchange are the most common mechanisms controlling wastewater treatment using mineral adsorbents. Besides the mentioned parameters, the $\mathrm{pH}$, temperature, adsorption time, and adsorbent dosage are also considered vital parameters controlling the adsorption process. The adsorption removal efficiency increases when the $\mathrm{pH}$ increases and the initial concentration decreases ${ }^{23}$.

Using natural minerals could be cost-effective. However, the removal efficiency might decrease after a few cycles ${ }^{24}$. Therefore, different modification methods, such as calcination and impregnation, have been proposed to enhance the removal efficiency of such adsorbents ${ }^{25}$. However, these modifications incur additional costs to the process and release new chemical agents into the environment. Grafting functional groups could synthesize ecofriendly and multifunctional adsorbents suitable for treating various types of wastewaters. The preparation of twodimensional nanosheets and one-dimensional nanotubes-based clay adsorbents might lead to innovative low-cost and highperformance adsorbents.

\section{Magnetic adsorbents}

Magnetic adsorbents are a specific material matrix that hosts iron particles (usually magnetic nanoparticles, such as $\left.\mathrm{Fe}_{3} \mathrm{O}_{4}\right)^{26}$. The base material could be carbon, CS, polymers, starch, or biomass. As illustrated in Fig. 2, the adsorption process is affected by the magnetic field, surface charge, and redox activity characteristics. They showed low-cost, easy-synthesis, extraordinary surface charge, and reusability. Many magnetic adsorbents were proposed

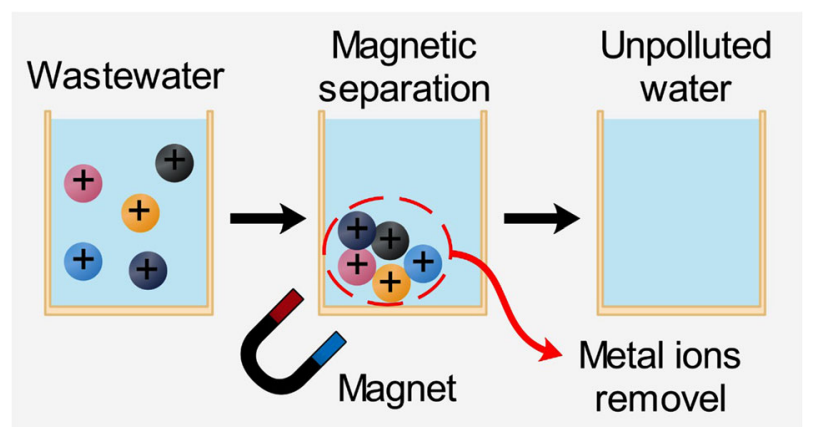

Fig. 2 Adsorption process via magnetic adsorption. The magnetic adsorbent particles adsorb the metal ions and sequentially accumulated; thus, the wastewater is treated.

in the literature, such as zero-valent iron nanoparticles (ZVI NPs), iron oxides (hematite $\left(\mathrm{a}-\mathrm{Fe}_{2} \mathrm{O}_{3}\right)$, maghemite $\left(\gamma-\mathrm{Fe}_{2} \mathrm{O}_{3}\right)$, magnetite $\left.\left(\mathrm{Fe}_{3} \mathrm{O}_{4}\right)\right)$, and spinel ferrites. The mechanism and kinetics of the sorption process rely on several parameters, such as surface morphology and adsorbent magnetic behavior. They are also affected by experimental conditions such as $\mathrm{pH}$, irradiation time, adsorbent concentration, wastewater temperature, and the initial dosage of pollutants ${ }^{27}$. The presence of iron particles in adsorbent is very efficient in metal ions removal from effluent ${ }^{28}$.

Some studies have focused on coating $\mathrm{Fe}_{3} \mathrm{O}_{4}$ particles for removing heavy metal ions. Co-precipitation, high-gravity technology, and grafting are the most commonly used methods ${ }^{29}$. The grafting method was considered a preferable choice because it is flexible and straightforward. However, it strongly depends on the active hydroxyl on the surface of $\mathrm{Fe}_{3} \mathrm{O}_{4}$ particles and the number of active functional groups. The produced adsorbents were not adequately cyclic stable, which is a barrier facing the commercialization of this method. Additional details about different magnetic adsorbents can be found in Supplementary Table 5 .

\section{Biosorbents}

The most recent research studies in using biosorption for wastewater treatment are listed in Supplementary Table 6. The presence of numerous functional groups (i.e., carboxyl, amino, hydroxyl, phosphate, thiol, etc.) on the surface expedite the biosorption process ${ }^{30}$. Generally, the interaction between pollutants and the surface of biosorbent can occur through electrostatic interaction, aggregation, complexation/coordination, microprecipitation, ion exchange, reduction, or oxidation ${ }^{31}$. The solution $\mathrm{pH}$ affects the biosorbent surface charge density and ionization of functional groups located on the biosorbent surface $^{32}$. When $\mathrm{pH}$ is low, cations are almost stable and can be bonded to the biosorbent surface. On the other hand, at higher $\mathrm{pH}$ values, the solubility of metal cations decreases with the possibility of a precipitation phenomenon.

The biosorbent amount is a vital factor affecting the removal efficiency due to offering more vacant biosorption sites. The biosorbent capacity could increase at higher temperatures due to decreased solution viscosity, reduction in Gibb's free energy, and bond rupturing. These reasons increase the collision frequency (mobility and kinetic energy) between biosorbent and metal ions and enhance the biosorbent active sites, leading to a higher affinity ${ }^{31}$. In turn, the bonding force between biosorbent and pollutants could decline at higher temperatures, and thus the biosorbent sorption uptake reduces. It was elucidated that the removal efficiency increases as the mixing agitation rate increases ${ }^{33}$. 


\section{Metal-organic frameworks adsorbents}

Metal-organic frameworks (MOFs) are generally synthesized via reticular synthesis in which metal ions are strongly bonded to organic linkers. Researchers proposed thousands of MOFs. It was noticed that most of the organic ligands used to form many MOFs are very expensive and toxic ${ }^{34}$. Zirconium-MOFs family (such as UiO-66) is promising nanostructure materials for sorption applications due to the easy incorporation of functional groups and hydrolytic-thermal stability such as amine, carboxylic, hydroxyl, and oxygen ${ }^{35}$ or by using the cross-linking method ${ }^{36}$. Compositebased MOF adsorbents could obtain further enhancement in the adsorption capacity of MOFs. Supplementary Table 7 lists the uptake of different MOFs towards several heavy metal ions in wastewater.

Despite the exciting features of MOFs and their good capability to remove heavy metal ions, they have micropores (i.e., tiny pores) inaccessible for some target metals. Also, most of them have low stability in water. $\mathrm{Mn}, \mathrm{Fe}$, and $\mathrm{Cu}$ have been used to form MOFs, but most of them resulted in poor chemical stability ${ }^{37-50}$. Therefore, further research is still needed to tune the MOFs' structure and scale up these materials to implement them into industrial wastewater applications. Moreover, different functionalization methods should be proposed and applied to enhance MOFs' stability and sorption kinetics.

The reported maximum uptakes of heavy metal ions for a proper adsorbent are listed in Table 2.

\section{MEMBRANE-BASED FILTRATION AND SEPARATION}

Over the years, technological advancement in membrane development has led to an increase in the use of membranes for filtration and extraction of heavy metal ions from wastewater. A simplified schematics for different membrane-based filtration processes is illustrated in Fig. $3 a-c$, while Fig. $3 d$ demonstrates various pollutants that can be separated by different membrane techniques ${ }^{51}$.

Table 2. Heavy metal adsorption onto nanoporous adsorbents with the highest capacity.

\begin{tabular}{llll}
\hline Heavy metal & Adsorbent & $\begin{array}{l}\text { Adsorption } \\
\text { capacity }(\mathrm{mg} / \mathrm{g})\end{array}$ & Ref. \\
\hline $\mathrm{Pb}^{2+}$ & Polyrhodanine/ MWCNTs & 8118.0 & 38 \\
$\mathrm{Cu}^{2+}$ & Polyvinylpyrrolidone-reduced & 1689.0 & 39 \\
& GO (PVP-rGO) & & \\
$\mathrm{Cd}^{2+}$ & Polyvinyl alcohol /zeolite & 838.7 & 40 \\
& nanofibrous & & \\
$\mathrm{Cr}^{3+}$ & N-MCNPs & 638.0 & 41 \\
$\mathrm{Cr}^{6+}$ & GSC & 2859.0 & 42 \\
$\mathrm{Co}^{2+}$ & PAMAM/CNT & 494.0 & 43 \\
$\mathrm{Fe}^{2+}$ & MNR & 127.0 & 44 \\
$\mathrm{Zn}^{2+}$ & PAMAM/CNT & 470.0 & 43 \\
$\mathrm{Ni}^{2+}$ & Coconut husk & 404.5 & 45 \\
$\mathrm{Hg}^{2+}$ & MSWCNT-CoS & 1666.0 & 46 \\
$\mathrm{As}^{3+}$ & PAMAM/CNT & 432.0 & 43 \\
$\mathrm{Mn}^{2+}$ & MCS & 200.9 & 47 \\
$\mathrm{Au}^{3+}$ & CSGO5 & 1076.7 & 20 \\
$\mathrm{UO}_{2}{ }^{2+}$ & SPG & 403.8 & 48 \\
$\mathrm{U}^{6+}$ & CCM & 392.7 & 49 \\
$\mathrm{Sb}^{3+}$ & Chitosan functionalized iron & 138.8 & 50 \\
& nanosheet & & \\
\hline
\end{tabular}

\section{Ultrafiltration}

Ultrafiltration (UF) is used at low transmembrane operating pressure (TMP). Because UF membrane pores may be larger than the heavy metal ions, additives may be bonded to metal ions to enlarge the size of the metal ions. Therefore, micellar enhanced ultrafiltration (MEUF) and polymer enhanced ultrafiltration (PEUF) are proposed.

MEUF is formed by bonding UF and surfactant. MEUF has high flux and high selectivity, leading to low-energy consumption, high removal efficiency, and less space demand ${ }^{52}$. MEUF is most suitable for wastewater whose heavy metals are in low concentrations ${ }^{53}$. In MEUF, a surfactant is mixed with wastewater in a concentration above the critical micellar concentration (CMC). Beyond CMC, surfactant monomers assemble and increase the creation of some micelles in the solution. The surfactant contains a hydrophobic tail and a hydrophilic head. The inner hydrophobic core of the micelles could solubilize organic matters (having low molecular weight) as a solubilizate, while the surface adsorbs counter metal ions on their surface due to electrostatic interactions ${ }^{54}$. Surfactants, whose electric charge is the opposite of the metal ions, usually attain the highest retentions ${ }^{55-57}$. In this regard, polyelectrolytes (PE), cationic surfactants, and anionic surfactants (e.g., sodium dodecyl sulfate (SDS)) are used for effective heavy metals extraction ${ }^{55}$.

A summary of different studies on the MEUF process is given in Supplementary Table 8. The performance of MEUF depends on several factors, including the added solutes, type of surfactant, operating conditions, and kind of membrane used.

PEUF is formed through the integration of UF and binding polymers. The functional groups of the bonding polymers could be sulfonate, phosphonic, carboxylated, or amine, and they are bonded via chelating or ionic bonds ${ }^{58}$. PEUF are also known as polymer-supported, complexation, polymer-assisted, size enhanced, and complexation enhanced ultra-filtrations. While permitting water and un-complexed components to permeate the membrane pores, the PEUF process blocks and extracts polymerbonded metal ions ${ }^{59}$.

A summary of studies conducted on PEUF is presented in Supplementary Table 9. PEUF shows effective polymer bonding, effective extraction, ability to recover and reuse complexation polymer of retentate, low-energy demands, and low-cost operation $^{51,55}$. However, the choice of appropriate watersoluble polymer macro-ligands remains the main challenge of developing this technology.

\section{Nanofiltration}

Nanofiltration (NF) is used to concentrate constituents whose molecular weight is $>1000 \mathrm{Da}$ and remove solutes whose size of $0.0005-0.007 \mu \mathrm{m}$ with molecular weights $>200 \mathrm{Da}^{60}$. Thus, the operating range of NF is between UF and reverse osmosis (RO) processes ${ }^{55}$. The NF membranes are composed of polymer composites of multiple-layer thin-film of negatively charged chemical groups. Anti-fouling NF membranes containing $\mathrm{CeO}_{2} /$ $\mathrm{Ce}_{7} \mathrm{O}_{12}$ and $\mathrm{PES}$ were synthesized through phase inversion and used to extract $\mathrm{Fe}^{3+}, \mathrm{Al}^{3+}, \mathrm{Co}^{2+}, \mathrm{Cd}^{2+}, \mathrm{Cu}^{2+}$, and humic acid from wastewater and reached extraction efficiency between 94 and $98 \%{ }^{61}$. Other studies are presented in Supplementary Table 10.

\section{Microfiltration}

Microfiltration (MF) employs a microporous membrane to remove micron-sized particles, bacteria, viruses, protozoa, contaminants, pollutants, etc., from a solvent/fluid/solution ${ }^{60}$. MF process is also a low pressure-driven membrane process, whose membrane pores are in the range of $0.1-10 \mu \mathrm{m}^{60}$. Some of the MF membranes are made of silica, ceramics, zirconia, alumina, PVC, polysulfone, PTFE, polypropylene, PVDF, polyamides, polycarbonate, cellulose acetate, cellulose esters, or composite materials. The commercial application 
(a)

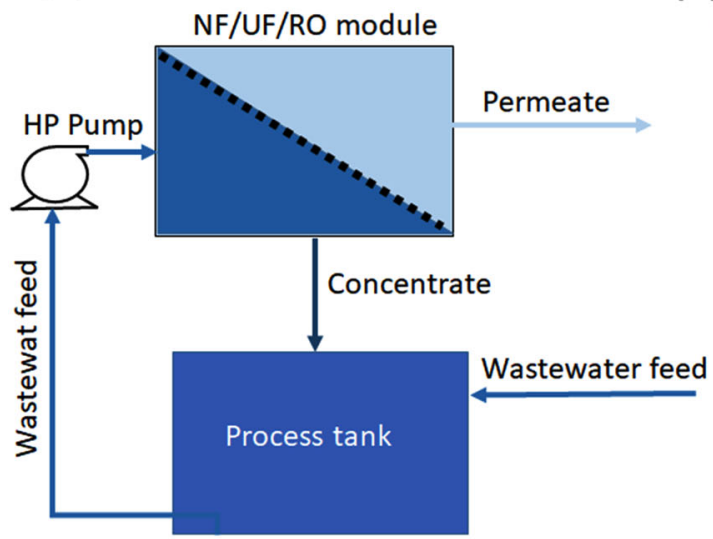

(b)

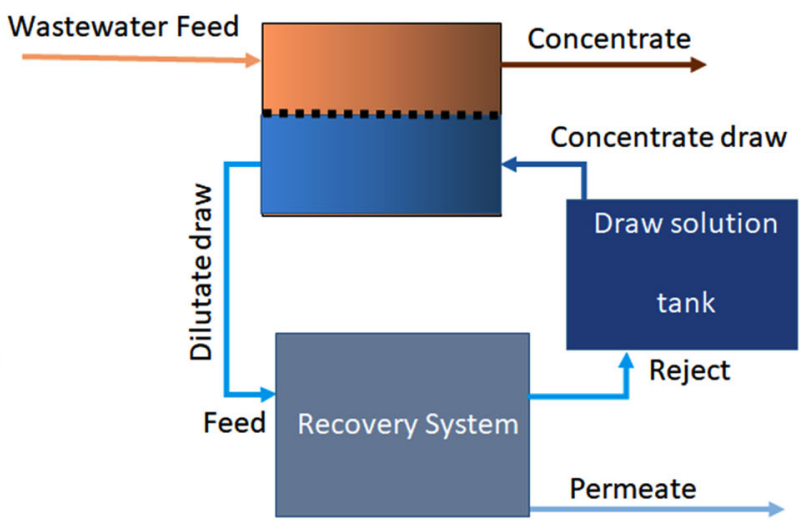

(c)

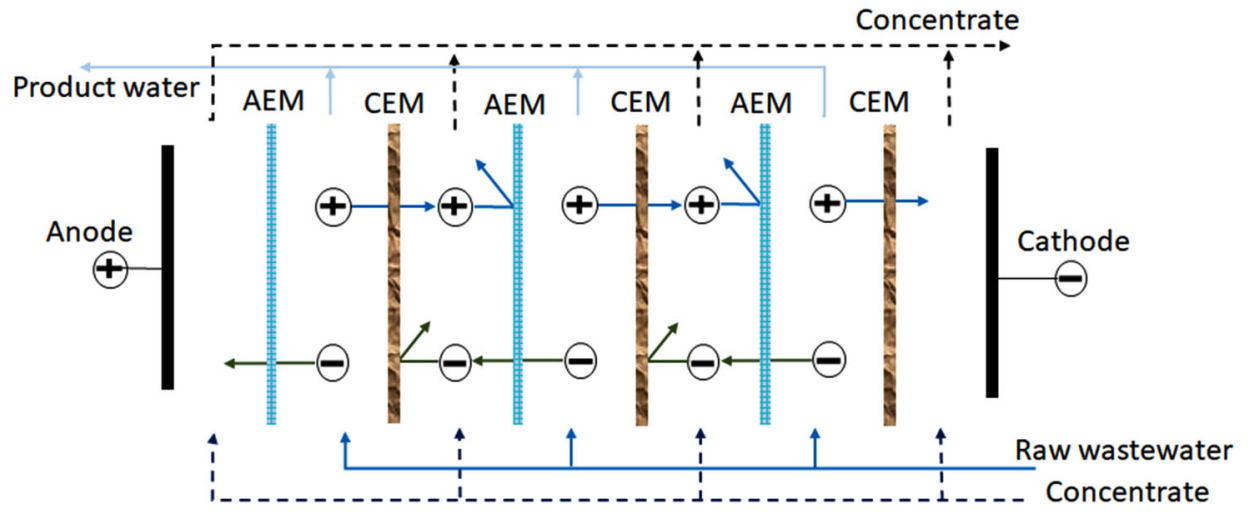

AEM: Anion exchange membrane; CEM: cation exchange membrane

(d)

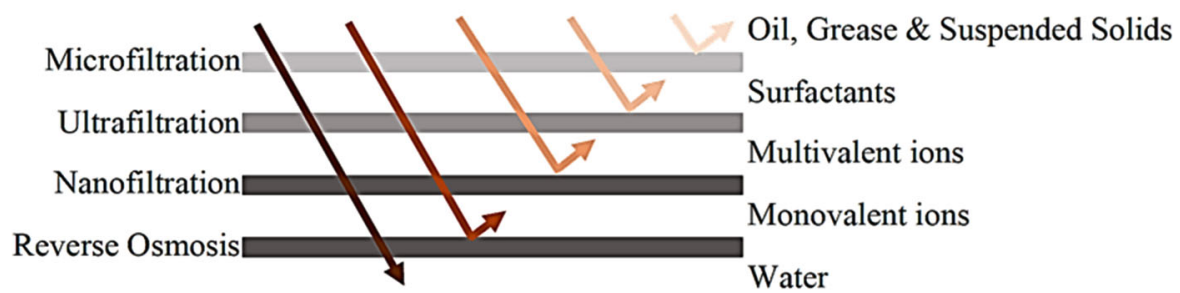

Fig. 3 Different membrane-based treatments for pollutants removal from wastewater and salty water. a nanofiltration, ultrafiltration, or reverse osmosis method, $\mathbf{b}$ forward osmosis process, $\mathbf{c}$ electrodialysis method in which alternative charged positive and negative membranes take place, and $\mathbf{d}$ the separation capabilities of different membranes against different pollutants.

of MF is widely found in pharmaceutical and biological industries. However, the application of the MF system may be found in particle removal of the rinse water in the semiconductor industry, sterilization of beer and wine, other juices and cider clarification, and wastewater treatment ${ }^{60}$. The application of MF in heavy metal removal has not drawn enough attention because of its low removal ability. However, it has been used by modifying membrane or chemical pre-treatment of the feed solution. Depending on the mode of application, the MF process is available in two main configurations: crossflow and dead-end. Some studies on MF are summarized in Supplementary Table 11.

\section{Reverse osmosis}

$\mathrm{RO}$ is a pressure-driven separation process that employs a semipermeable membrane (pore size $0.5-1.5 \mathrm{~nm}$ ) to allow only smaller molecules to pass. $\mathrm{RO}$ process reverses the normal osmosis process by applying pressure (20-70 bar) $>$ the osmotic pressure of the feed solution. The molecular size of the solutes blocked is usually in the range of $0.00025-0.003 \mu \mathrm{m}^{60}$. RO process could extract $95-99 \%$ of inorganic salts and charged organics ${ }^{60}$. RO process is compact and attained high rejection efficiency. However, membrane fouling and degrading are the major drawback of RO systems ${ }^{60}$. The RO separation process was used to extract heavy metal ions, including $\mathrm{Ni}^{2+}, \mathrm{Cr}^{6+}$, and $\mathrm{Cu}^{2+}$ from electroplating wastewater, with a removal efficiency of $>98.75^{62}$. Recently, RO has been used to purify industrial wastewaters from coster-field mining operations located in Victoria-Australia with mean extraction efficiency of $10 \%$, $48 \%, 82 \%, 66 \%$, and $95 \%$ for $\mathrm{Fe}^{3+}, \mathrm{Zn}^{2+}, \mathrm{Ni}^{2+}, \mathrm{As}^{3+}$, and $\mathrm{Sb}^{3+}$ respectively ${ }^{63}$. Other studies on RO heavy metals removal are summarized in Supplementary Table 12.

\section{Forward osmosis}

Forward osmosis (FO) is an osmosis process that requires a membrane to balance selectivity and permeated water flux ${ }^{51}$. 
In FO, a semi-permeable membrane separates a feed solution from the draw solution, as shown in Fig. 3b. The draw solution is usually at a higher osmotic pressure compared to the feed solution. Due to the osmotic pressure difference between the feed and draw solutions, water transports from the feed solution to the draw solution, thereby keeping the rejected solutes on the feed side and treated water on the draw solution ${ }^{64}$. FO does not require hydraulic pressure; thus, it is energy-saving. FO process is also environmentally friendly, easy cleaning, and low fouling; therefore, it is widely used in wastewater treatment ${ }^{64}$. Nevertheless, FO has limitations, such as draw solution re-concentration, membrane selection challenges, internal and external concentration polarization $^{65}$. Supplementary Table 13 summarizes the use of FO, including thin-film membranes.

\section{Electrodialysis}

Electrodialysis (ED) is used to separates ions at the expense of electric potential difference. ED uses a series of cation exchange membranes (CEM) and anion exchange membranes (AEM), alternatively arranged in parallel, to separate ionic solutes ${ }^{51}$. In the ED process, the anions pass through AEM, while cations pass through CEM. In such a case, the treated stream (diluate) is produced from half of the ED stack channels, while the concentrated stream is expelled from the other half, as shown in Fig. 3c. ED offers high water recovery, no phase change, no reaction, or chemical involvement ${ }^{66}$, and can operate over a wide range of $\mathrm{pH}$ values. However, ED also exhibits membrane fouling, high cost of membranes, and demand for electric potential.

$\mathrm{ED}$ has been used to separate $\mathrm{Ni}^{2+}, \mathrm{Pb}^{2+}$, and $\mathrm{K}^{+}$from synthetic solution through a novel ED heterogeneous CEM (consisting of 2acrylamido-2-methyl propane sulfonic acid-based hydrogel and PVC) to attain extraction efficiency of $96.9 \%, 99.9 \%$, and $99.9 \%$ for $\mathrm{Ni}^{2+}, \mathrm{Pb}^{2+}$, and $\mathrm{K}^{+}$, respectively ${ }^{67}$. A batch $\mathrm{ED}$ process was employed to recover $\mathrm{Pb}^{2+}$ and reached a maximum separation efficiency of $\sim 100 \%{ }^{68}$. A pilot-scale ED system has also been used to extract $\mathrm{Cu}^{2+}, \mathrm{Ni}^{2+}$, and traces of $\mathrm{Cd}^{2+}, \mathrm{Fe}^{3+}, \mathrm{Cr}^{6+}$ and $\mathrm{Zn}^{2+}$, and exceeded $90 \%$ removal rate ${ }^{69} . \mathrm{As}^{3+}$ and $\mathrm{As}^{5+}$ were removed from metallurgical effluent by ED and attained a removal efficiency of $91.38 \%{ }^{70}$.

\section{Other membrane-based methods}

Membrane distillation (MD) and liquid membrane (LM) are also used for wastewater treatment. MD is a hybrid thermally driven membrane separation process that consists of cold and hot compartments separated by a microporous hydrophobic membrane. MD allows only vapor to permeate its pores while blocking other molecules. MD exists in four configurations: direct contact $M D$, air gap MD, sweeping gas MD, and vacuum MD. MD process has been reported to achieve over $96 \%$ removal of $\mathrm{Ca}^{2+}, \mathrm{Mg}^{2+}$, $\mathrm{Fe}^{3+}$, and $\mathrm{Fe}^{2+71}$, and more than $99 \%$ for $\mathrm{As}^{3+}$ and $\mathrm{As}^{5+72}$.

On the other side, LM is made of a liquid phase or thin-layer organic phase, which acts as a barrier between two aqueous phases. LM is immiscible to the feed solution and retentate solution $^{51}$, and combined stripping and extraction processes in a single stage ${ }^{73}$. LM is highly selective, relatively efficient, and can achieve specific molecular recognition. However, the membrane's long-term stability is poor ${ }^{74}$. LM process exists as a supported liquid membrane (SLM), emulsion liquid membrane (ELM), bulk liquid membrane (BLM), and polymer inclusion membrane $(P I M)^{51}$. Among these types, the SLM process is an attractive alternative to traditional solvent extraction for heavy metal removal ${ }^{73}$. SLM achieved a removal efficiency of $89 \%$ for $\mathrm{Zn}^{2+}, \mathrm{Cd}^{2+}, \mathrm{Cu}^{2+}$, and $\mathrm{Fe}^{3+75}$.

\section{CHEMICAL-BASED SEPARATION}

Chemical methods for removing heavy metals from wastewater are mature and used early. In this section, the chemical-based methods will be discussed, including precipitation, coagulationflocculation, and flotation.

\section{Precipitation}

Chemical precipitation (the so-called coagulation precipitation) is broadly used in industries and is considered one of the most effective and mature methods. It changes the form of dissolved metal ions into solid particles to facilitate their sedimentation. The reagent coagulation (coagulant) precipitates metal ions by changing $\mathrm{pH}$, electro-oxidizing potential, or co-precipitation ${ }^{76}$. It is usually followed by the removal of sediments. A simple schematic of the chemical precipitation process is depicted in Fig. 4.

Hydroxide precipitation is broadly used due to its relatively inexpensive, simple, and tunable $\mathrm{pH}^{77}$. It is implemented by adding a hydroxide to the stirred wastewater to form insoluble metal hydroxide precipitates. For example, a metal ion could react with calcium hydroxide (lime) to produce metal hydroxide precipitates and calcium ions as:

Metal $^{n+}+\mathrm{Ca}(\mathrm{OH})_{2} \Leftrightarrow \operatorname{Metal}(\mathrm{OH})_{n} \downarrow+\mathrm{Ca}^{2+}$

It was found that $\mathrm{pH}$ values of 9-11 improved this process efficiency ${ }^{78}$. However, a high $\mathrm{pH}$ value is considered a disadvantage of this method since it requires a large dosage of precipitates. One of the most effective hydroxide precipitates for treating inorganic effluents of heavy metal concentration of $1000 \mathrm{mg} / \mathrm{L}$ is lime $\left(\mathrm{CaO} \text { or } \mathrm{Ca}(\mathrm{OH})_{2}\right)^{79}$. A summary of some hydroxide precipitation studies is presented in Supplementary Table 14. It can be seen that the majority of metals removed by this method are $\mathrm{Zn}^{2+}, \mathrm{Cu}^{2+}, \mathrm{Ni}^{2+}, \mathrm{Pb}^{2+}$, and $\mathrm{Cr}^{3+}$. In addition to the need for the high dosage to get optimal $\mathrm{pH}$, there are some drawbacks, such as relatively large volumes of sludge leading to dewatering, disposal issues, amphoteric, and the inhabitation of metal hydroxide precipitation with the presence of complexing agents.

The sulfide participation method distinguishes itself by higher removal efficiency and lesser dissolved solids increment than the hydroxide method. This method was reported to treat toxic heavy metal ions ${ }^{80}$. Lower sulfide results in a higher zinc concentration in the effluent, while higher sulfide leads to a malodor problem due to high residual sulfide. Also, it could produce hydrogen sulfide gas which is malodorous and toxic. For these reasons, the sulfide precipitation is recommended to be executed at a neutral $\mathrm{pH}^{81}$. The metal sulfide precipitations could follow Eq. (2) reaction,

Metal $^{n+}+\mathrm{S}^{2-} \Leftrightarrow \operatorname{Metal}_{n} \mathrm{~S} \downarrow$

Supplementary Table 15 summarizes the metal ions removal using sulfite precipitations. The toxicity of sulfide and its high cost are the most shortcomings.

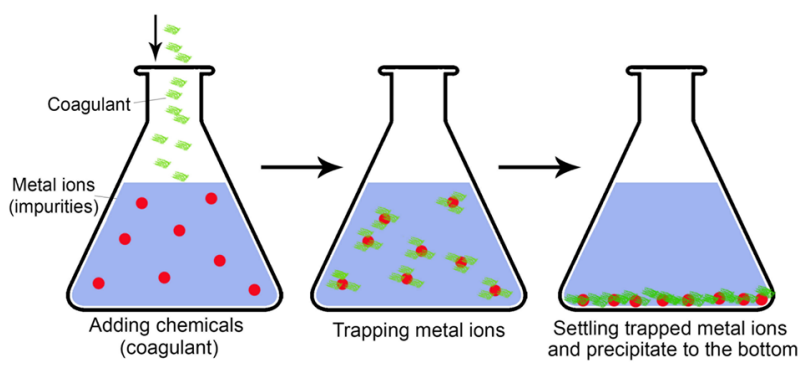

Fig. 4 A simple schematic of the chemical precipitation process. The coagulant is added to wastewater and stirred to trapping metal ions that settle and precipitate to the bottom of the container. 
As an alternative method to hydroxide precipitation, carbonate precipitation shows good effectiveness and optimum precipitation at lower $\mathrm{pH}$ values ${ }^{82}$. It could be achieved using sodium carbonate or calcium carbonate. The classical carbonates can be formed based on Eq. ( 3 and 4$)^{83}$ :

Metal $^{n+}+n \mathrm{NaCO}_{3} \Leftrightarrow n \operatorname{Metal}\left(\mathrm{CO}_{3}\right)+n \mathrm{Na}^{+}$

$n$ Metal $\left(\mathrm{CO}_{3}\right)+\mathrm{H}_{2} \mathrm{O} \Leftrightarrow \mathrm{CO}_{2} \uparrow+(\mathrm{MeOH})_{n} \mathrm{CO}_{3} \downarrow$

It could have less sludge volume, but it could release $\mathrm{CO}_{2}$ bubbles and needs higher reagents for efficient precipitation ${ }^{83}$. Supplementary Table 16 lists some studies concerning carbonate precipitation. It can be seen that copper and manganese are the major metals removed by this technology. Zinc and lead could also be removed efficiently.

Fenton reaction is usually used to improve the removal efficiency of the chemical precipitation methods. The Fenton or Fenton-like oxidation is used for the de-complexation of heavy metal complexes. However, the $\mathrm{pH}$ is adjusted by the chemical precipitation mechanism (e.g., $\mathrm{NaOH}$ ). Fenton chemistry is not straightforward, and it is performed through numerous reactions, depending upon various active intermediates, such as $\left[\mathrm{Fe}^{\mathrm{IV}} \mathrm{O}\right]^{2+}$ and hydroxyl radicals ${ }^{84,85}$. The classical Fenton reaction is ${ }^{86}$ :

$$
\begin{aligned}
& \mathrm{Fe}^{2+}+\mathrm{H}_{2} \mathrm{O}_{2} \Leftrightarrow \mathrm{Fe}^{3+}+\mathrm{HO} \cdot+\mathrm{HO}^{-} \\
& \mathrm{HO} \cdot+\text { dye } \Leftrightarrow \text { oxidized dye }+\mathrm{H}_{2} \mathrm{O}
\end{aligned}
$$

$\mathrm{Fe}^{3+}-\mathrm{H}_{2} \mathrm{O}_{2}$ (Fenton-like ${ }^{87}$ ) and $\mathrm{Fe}^{0}-\mathrm{H}_{2} \mathrm{O}_{2}$ (advanced Fenton ${ }^{88}$ ) are also represented as an alternative for $\mathrm{Fe}^{2+}-\mathrm{H}_{2} \mathrm{O}_{2}$. Additional detailed examples of using the Fenton-integrated chemical precipitation method are summarized in Supplementary Table 17.

Some metals are represented in small volumes in bulk wastewater, such as radionuclides. The removal of radioactive metals is listed in Supplementary Table 18.

\section{Coagulation and flocculation}

Coagulation is the destabilization of colloids by neutralizing the forces that keep them parted, while flocculation is the agglomeration of destabilized particles ${ }^{89}$. Traditional coagulants are aluminum, ferrous sulfate, and ferric chloride, using to neutralization of ion charges. Flocculation bonds the particles forming large agglomerates with the help of a flocculant, such as polyaluminum chloride (PAC), polyferric sulfate (PFS), polyacrylamide (PAM), and other macromolecule flocculants ${ }^{90}$. The PE were reported as one of the most practical flocculations, but the produced sludge might be toxic ${ }^{89}$. The flocculants are generally not natural and nonbiodegradable ${ }^{91}$.

The process is illustrated in Fig. 5, including the sedimentation. Some weaknesses are toxicity and health hazardousness of inorganic coagulants, a large volume of sludge, selective for some metals and inefficient in emerging contaminants, increasingly effluent color, inefficient when using natural coagulants, and complex of scaling up ${ }^{92}$. Supplementary Table 19 summarizes some of the studies conducted on coagulation-flocculation for heavy metal removal from different wastewater sources. The typical heavy metals removed by this method include $\mathrm{Cu}^{2+}, \mathrm{Pb}^{2+}$ and $\mathrm{Ni}^{2+}$. Other metals such as $\mathrm{As}^{2+}, \mathrm{Se}^{2+}, \mathrm{Cr}^{2+}, \mathrm{Sb}^{3+}, \mathrm{Sb}^{5+}, \mathrm{Ag}^{2+}$ could also be efficiently removed.

\section{Flotation}

Flotation is used to remove various metal ions. The general schematic of the flotation process is shown in Fig. 6. Dissolved air flotation, ion flotation, and precipitation flotation were extensively studied. In the dissolved air flotation, air (or gas) is fed to wastewater to generate micro-bubbles that could attach the metal ions, developing lower density agglomerates, leading to raising

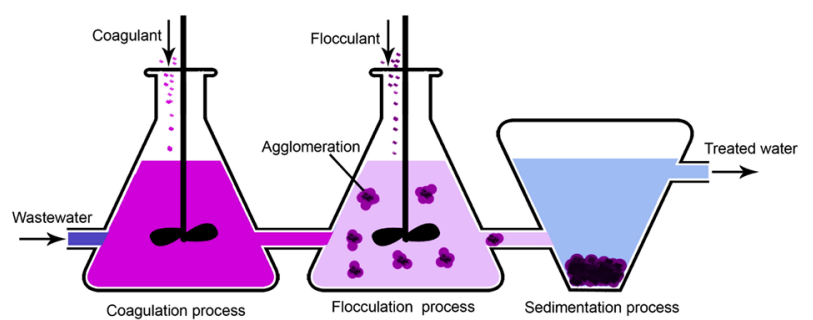

Fig. 5 An illustrative schematic of the coagulation-flocculation treatment process. Coagulation and flocculation could be either two sequential processes or one process. The sedimentation process could be replaced with filtration or another method.

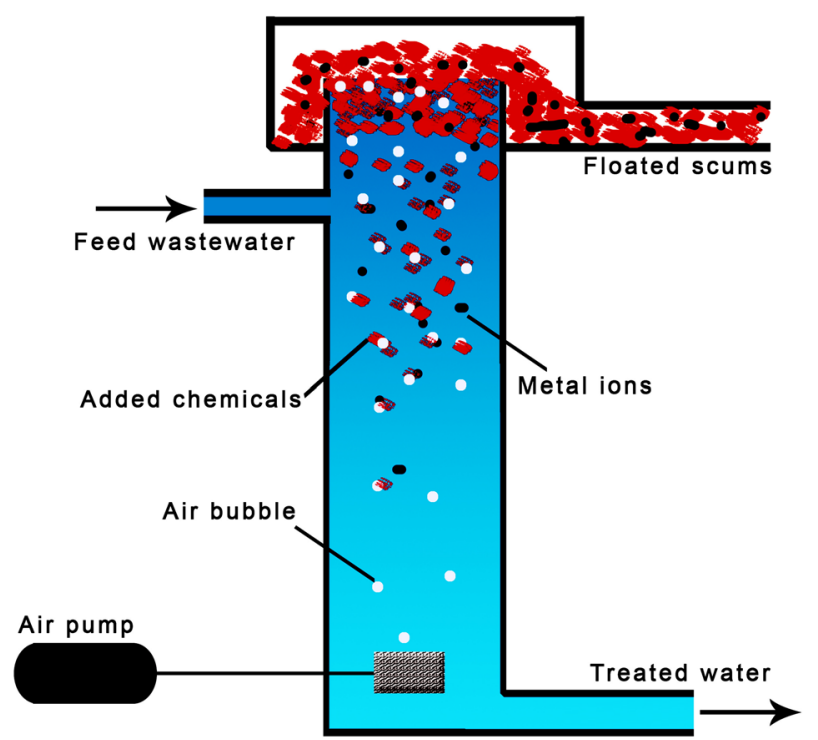

Fig. 6 An illustrative schematic of the flotation treatment process. Chemicals such as collectors are added to be attached with metal ions and microbubbles, leading to lower density agglomerates floated and removed from the top of the treatment column.

the flocs through the wastewater. The accumulated slug at the top surface can easily be removed ${ }^{93}$.

The ion flotation process relies on the increase of hydrophobicity of metal species by using surfactants; therefore, the hydrophobic species are removed by air bubbles. The added surfactant facilities as collectors, while frothers control the indexes of ion flotation ${ }^{94}$. When the concentration of metal ions is low within a large quantity of wastewater, the ion flotation appears inefficient $^{95}$. The ion flotation process showed low-energy consumption, limited volume demands, reduced sludge volumes, and selective treatment ${ }^{96}$. The precipitation flotation process is basically a chemical precipitate process that implements microbubbles. That precipitation flotation takes a short time to complete efficiently ${ }^{97}$. Generally, the flotation processes have advantages such as rapid operation, compact process, and a moderate cost.

Significant attention has recently been paid to ion flotation among all flotation processes, as observed from Supplementary Table 20. Since ion flotation depends on surfactants as collectors, efficient and non-toxic surfactants are required. Chemical synthetic surfactants have been introduced to have strong collection ability, good selectivity, and easy construction. However, the cost and toxicity issues limit them. On the other side, biosurfactants sound more environmentally friendly, but they 
exhibited low removal rates, large dosage quantity, and longtime process $^{94}$. In this regard, nanoparticles have been proposed as new collectors that showed both benefits of synthetic- and biosurfactants ${ }^{94}$.

\section{ELECTRIC-BASED SEPARATION}

In this section, different electrochemical methods (i.e., electrochemical reduction (ER), EC, electroflotation (EF), and electrooxidation (EO)), and ion exchange method are discussed.

\section{Electrochemical treatment}

In an electrochemical system, oxidation is performed at the anode (positive side), where electrons transfer to the cathode (negative side), at which the reduction process occurs. These two chemical reactions are called redox (reduction-oxidation), leading to water purification through metal removal. For example:

$$
\text { Metal }^{n+}+\mathrm{nH}_{2} \mathrm{O} \rightarrow \underbrace{\text { Metal }^{\mathrm{m}+}\left(\mathrm{H}_{2} \mathrm{O}\right)_{n}}_{\text {in }} \text { solution } \downarrow+\underbrace{\mathrm{me}^{-}}_{\text {on }} \text { metal }
$$

Selection of the anode and cathode mainly decides the type of the electrochemical method and influences the removal efficiency towards specific metal ions. Figure 7a shows different types of electrode arrangements, namely: monopolar electrodes in series (MP-S) arrangement, monopolar electrodes in parallel (MP-P) arrangement, and bipolar electrodes in series (BP-S) arrangement ${ }^{98}$. MP-S and MP-P are preferable from the economic point of view and also yield high products.

The electrochemical processes are primarily classified into ER, $E C, E F$, and EO processes. In the ER method, also known as electrodeposition and electroplating, targeted atoms or molecules are deposited on the surface of the cathode, as shown in Fig. 7b. Sludge, which requires further treatment, is not formed in this (a)

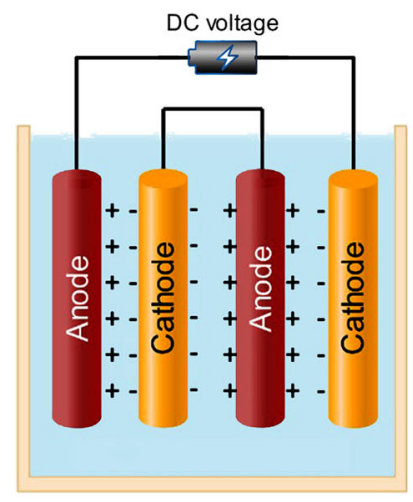

Monopolar in series

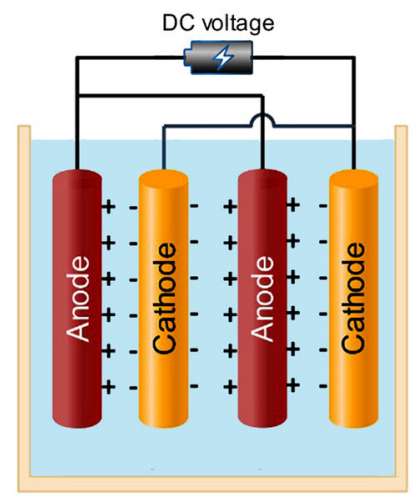

Monopolar in parallel

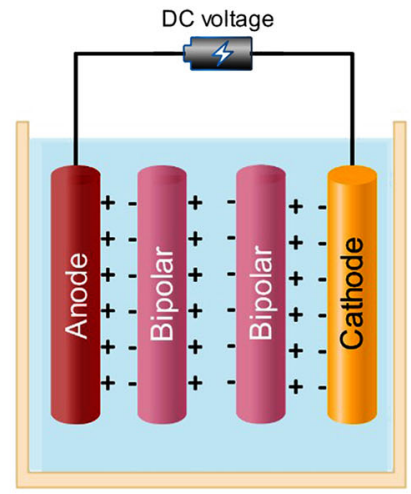

Bipolar in series (c)

(b)

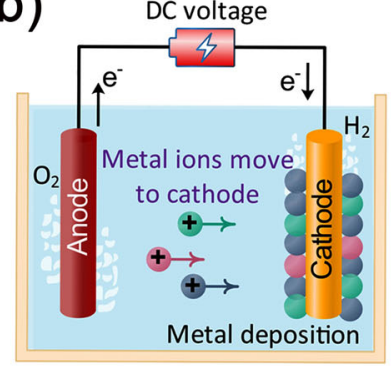

(e)

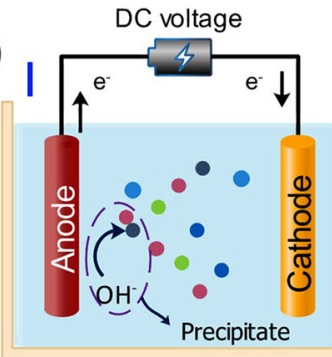

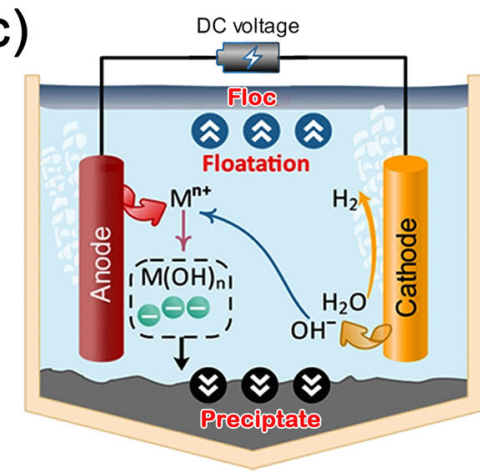

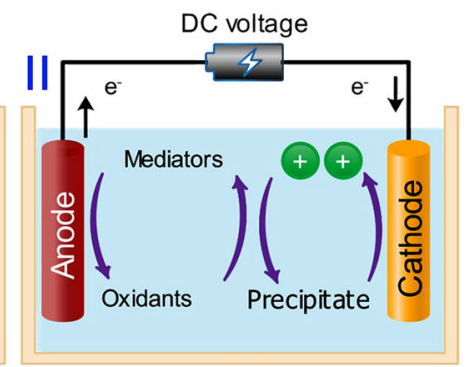

(d)

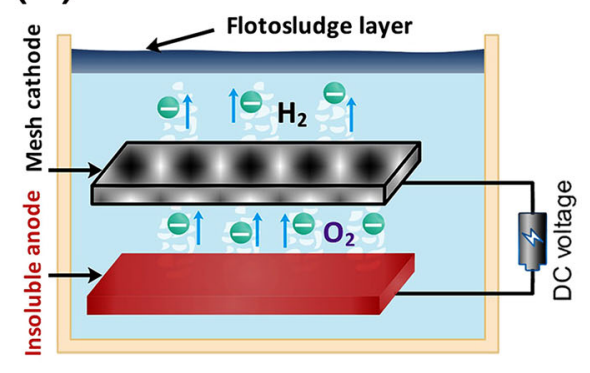

(f)

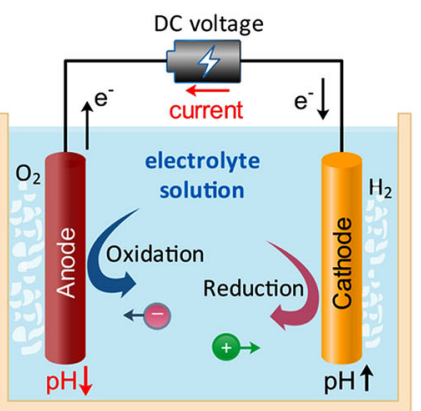

Fig. 7 Electrochemical methods and arrangements used for heavy metals removal. a Different arrangements of electrodes in electrolysis cell (i.e., monopolar electrodes in series (MP-S), monopolar electrodes in parallel (MP-P), and bipolar electrodes in series (BP-S)), b mechanism of the electrochemical reduction method in which positive metal ions are deposited over the cathode, c electrocoagulation process showing the flotation and precipitation of metal ions, $\mathbf{d}$ basic electroflotation methods-anions are released from anode to combine with cations (metal ions) and then floating over the water, e electrochemical oxidation (EO) process ((I) direct EO in which the ions react with OH and precipitate or (II) indirect EO in which mediators are used to forming oxidants that interact with the ions to be removed), and $\mathbf{d}$ electro-Fenton process in which $\mathrm{OH}^{-}$is released at anode and reacts with metal ions, and hence wastewater is purified due to precipitation. 
treatment. It is worth noting that cathodes with high overpotential toward hydrogen evolution are more efficient in pollutant removal/reduction ${ }^{99}$. Supplementary Table 21 lists the most recent research studies of heavy metals removal using ER and its conditions. The cathodes made of carbon-based or sulfur mixture with different ratios in acidic conditions are suitable for removing $\mathrm{Hg}^{2+}, \mathrm{Cd}^{2+}, \mathrm{Pb}^{2+}$, and $\mathrm{Cu}^{2+}$ from wastewater ${ }^{100}$. Iridium oxide-coated titanium anode was found as a perfect material for $\mathrm{Cd}^{2+}$ removal with an efficiency of $100 \%$ regardless of its initial concentration ${ }^{101}$. More attention should be paid to the reactor design and the operating conditions to enhance the performance of the wastewater treatment ${ }^{101}$. Energy consumption is a barrier that should be solved to commercialize this type of treatment in industrial applications.

In the EC method, steel (iron) or aluminum electrodes, which are non-toxic and reliable, are mostly used ${ }^{102}$. The mechanism of the EC method is sequentially as; dissolving cations of anodic metal (Eq. (8)), hydroxo complex formation (coagulants, Eq. (9)), aggregate stability and phase separation, and precipitation and flotation.

Metal $\rightarrow$ Metal $^{n+}+$ ne $^{-}$

$2 \mathrm{H}_{2} \mathrm{O}(\mathrm{I})+2 \mathrm{e}^{-} \rightarrow \mathrm{H}_{2}(\mathrm{~g})+2 \mathrm{OH}^{-}$

Cations from anode destabilize colloidal particles and also form polymeric hydroxide complex metal ions (i.e., coagulants), which react with pollutants (negatively charged) present in wastewater as:

$\operatorname{Metal}^{n+}(a q)+\mathrm{nOH}^{-} \rightarrow \operatorname{Metal}(\mathrm{OH})_{\mathrm{n}}(s) \downarrow$

Therefore, metal hydroxide (larger particles) whose density is higher than water forms and precipitates (settle down), while floc (fine particles) floats, as illustrated in Fig. 7c. The coagulants are generated in situ due to anode oxidation, which is considered a further advantage of EC methods over other technologies. Supplementary Table 22 summarizes the most recent EC studies for heavy metal removal from wastewater. Generally, it was found that lower energy consumption and higher removal efficiency are achieved when the alternating current is used rather than the direct current. Also, the rise in temperature, voltage, and $\mathrm{pH}$ reduces the test duration.

EC drawbacks are the electrodes passivation and relatively high energy consumption ${ }^{103}$ and the challenge of large-scale applications at lower energy consumption ${ }^{104}$. Many successful approaches were proposed to alleviate the passivation of the electrode, such as aggressive ion addition, alternating current operation, polarity reversal operation, ultrasonication, mechanical cleaning of electrodes, chemical cleaning of electrodes, hydrodynamic scouring. However, each route has drawbacks, such as generating hazardous byproducts, costly, additional treatment, and infrastructure, and increasing sludge production ${ }^{105}$. Accordingly, the EC process is still not fully mature applications.

The mechanism of EF is mainly based on carrying out water electrolysis on insoluble electrodes, while the flotation effect is introduced to facilitate the treatment process ${ }^{106}$, as sketched in Fig. $7 \mathrm{~d}$. So, the process efficiency depends on tiny $(\sim 0.15 \mathrm{~mm})$ and uniform bubbles. Details of EF separation are listed in Supplementary Table 23. It can be concluded that Ti-based anodes were widely used in the EF process ${ }^{107}$. They are insoluble, noncorrosive, and have high catalytic activity reactions with $\mathrm{Cl}_{2}$ and $\mathrm{O}_{2}$ in the electrolyte ${ }^{108}$. It was showed that the optimal pollutant concentration is in a range of $10-100 \mathrm{mg} / \mathrm{L}$, while the maximum could be $200 \mathrm{mg} / \mathrm{L}^{109}$. The removal efficiency of the EF process toward heavy metal is limited due to low $\mathrm{O}_{2}$ evolution overpotentials ${ }^{107}$. Therefore, hybridization between EF, membrane, and EC was a promising approach to improve the overall system performance to remove heavy metals ${ }^{110}$.

The mechanism of removing compounds from wastewater using EO is direct and indirect, as shown in Fig. 7e. The direct mechanism is simple. The performance of the indirect oxidation by chlorine depends on the $\mathrm{NaCl}$ concentration and is independent of current intensity ${ }^{111}$. The pollutants exchange electrons directly with the anode surface, and the polymeric layer is formed on the anode surface, leading to electrode deactivation and degrading efficiency. Oxidized contaminants appear in the solution when the organic pollutants interact with oxidants, as shown in Fig. 7e. The following equations describe the EO process:

Metal $+\mathrm{H}_{2} \mathrm{O} \rightarrow \operatorname{Metal}(: \mathrm{OH})+\mathrm{H}^{+}+\mathrm{e}^{-}$

$\operatorname{Metal}(: \mathrm{OH}) \rightarrow$ Metal O $+\mathrm{H}^{+}+\mathrm{e}^{-}$

Metal O $+\mathrm{R} \rightarrow \mathrm{M}+\mathrm{RO}$ and Metal $\mathrm{O} \rightarrow \mathrm{M}+\frac{1}{2} \mathrm{O}_{2}$

Supplementary Table 24 lists the efficiency of the EO process at specific operating conditions using different anodes. $\mathrm{Pt}, \mathrm{Au}, \mathrm{Mn}$, boron-doped diamond $\left(\mathrm{PbO}_{2}\right)$, and mixed metal oxide (MMO) (such as $\mathrm{SnO}_{2}, \mathrm{PbO}_{2}, \mathrm{Ti} / \mathrm{TiO}_{2}, \mathrm{IrO}_{2}, \mathrm{Sb}_{2} \mathrm{O}_{5}, \mathrm{RuO}_{2}$ ) are widely used as anodes $^{112}$. The main advantages and disadvantages of several anode materials are listed in Table 3. Highly efficient anode materials are expensive. So, other materials should be proposed to compromise efficiency and cost. Moreover, the presence of different types of metal ions in wastewater affects treatment efficiency. Hence, there is an urgent need to find efficient anode materials with high efficiency in diluted solutions. Future trends should investigate the effectiveness of integrating EO with other water technologies to overcome operational issues. Different electrochemical treatment processes are compared in Table 4.

Table 3. Comparison between different types of anodes used in the EO method.

\begin{tabular}{|lll}
\hline Anode material & Advantages & Disadvantages \\
\hline $\mathrm{Pt}, \mathrm{Au}, \mathrm{Mn}$ & - Stable and inert. & - Expensive. \\
& - More suitable for lab testing. & - Not suitable for industrial applications. \\
$\mathrm{PbO}_{2}$ & - Outstanding repeatability properties. & - Low mineralization efficiency. \\
$\mathrm{MMO}$ & - Relatively inexpensive. & - Toxic Pb could be formed. \\
& - Suitable for mineralizing organics & - Low efficiency in industry applications \\
& - Relatively inexpensive. & - Toxic Sb could be formed. \\
$\mathrm{BDD}$ & - High stability. & - Uneven coating. \\
& - Good conductivity properties. & - Costly. \\
& - High potential for mineralizing organics. & - Not efficient in highly diluted wastewater. \\
& - Superior conduction characteristics even at low temperatures. & - Overrising current density more than a limited one.
\end{tabular}


Table 4. Comparison between different methods of electrochemical treatment processes.

\begin{tabular}{|c|c|c|}
\hline Method & Pros & Cons \\
\hline Electro-deposition & $\begin{array}{l}\text { - High ability to recover valuable materials. } \\
\text { - Chemicals are not added. } \\
\text { - Selective process. } \\
\text { - Low operational cost. } \\
\text { - Water disinfection. }\end{array}$ & $\begin{array}{l}\text { - High sensitivity of the treatment efficiency towards the type of } \\
\text { wastewater. } \\
\text { - Side reactions of hydrogen generation and oxygen reduction } \\
\text { negatively affect the process efficiency. }\end{array}$ \\
\hline Electrocoagulation & $\begin{array}{l}\text { - Potential of treating oily water. } \\
\text { - Coagulants are generated in situ by the electrical } \\
\text { dissolution of metal electrodes. } \\
\text { - Forming secondary pollutants is not existing. } \\
\text { - Floc formed is easily removed as it is large and stable. } \\
\text { - Sludge formed is stable, non-toxic, and easily removable. } \\
\text { - } \mathrm{H}_{2} \text { generated helps in removing tiny particles. } \\
\text { - Complete automation of the process is feasible. } \\
\text { - Simplicity in operating, and no chemicals are added. } \\
\text { - Producing colorless, odorless, and clear water. }\end{array}$ & $\begin{array}{l}\text { - Probability of cathode passivation is high, causing a low efficiency. } \\
\text { - High energy consumption. } \\
\text { - As anode dissolves in solution, it should be replaced periodically. } \\
\text { - Produce harmful secondary pollutants. }\end{array}$ \\
\hline Electroflotation & $\begin{array}{l}\text { - Short process time. } \\
\text { - Forming a stable sludge layer. } \\
\text { - No additional chemicals are added. } \\
\text { - Possibility of extracting pollutants of size from } 10 \text { to } \\
100 \mu \mathrm{m} \text {. } \\
\text { - Relatively low-energy consumption (from } 100 \text { to } 3000 \mathrm{Wh} / \\
\mathrm{m}^{3} \text { ). } \\
\text { - No pollution formed. }\end{array}$ & $\begin{array}{l}\text { More suitable for small scale. } \\
\text { - Difficult control of the system } \mathrm{pH} \text {. } \\
\text { - Generation of } \mathrm{Fe}^{3+} \text {-carboxylate complex in PEF process. }\end{array}$ \\
\hline Electrooxidation & $\begin{array}{l}\text { - No need for additional chemicals. } \\
\text { - No tendency to form secondary pollutants. } \\
\text { - Oxidize highly toxic pollutants. }\end{array}$ & - Polarization, passivation, and corrosion of electrodes. \\
\hline
\end{tabular}

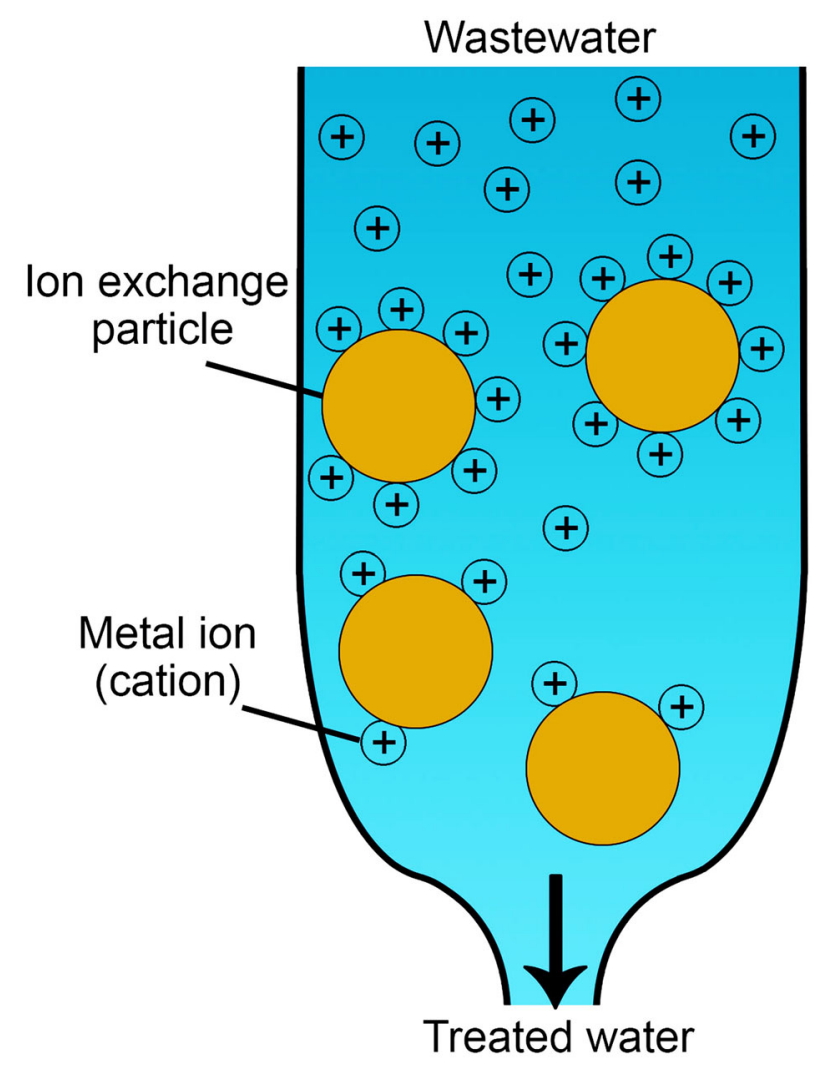

Fig. 8 Schematic of the ion exchange process. The metal ions (cations) of wastewater occur in the position of those in the ion exchange particles (such as $\mathrm{H}^{+}$and $\mathrm{Na}^{+}$). Anions could also be removed by this method.

\section{lon exchange treatment}

The ion exchange method is a reversible chemical reaction used to replace the undesirable metal ion with harmless and environmentally friendly ones ${ }^{113}$. A heavy metal ion is removed from a wastewater solution by attaching it to an immobile solid particle as a replacement with the solid particle cation, as shown in Fig. 8 . The material of solid ion-exchange particles could be either natural, e.g., inorganic zeolites, or synthetically produced, e.g., organic resins. The ion-exchange method can remove target (some or all) heavy metal ions, such as $\mathrm{Pb}^{2+}, \mathrm{Hg}^{2+}, \mathrm{Cd}^{2+}, \mathrm{Ni}^{2+}, \mathrm{V}^{4+}, \mathrm{V}^{5+}, \mathrm{Cr}^{3+}, \mathrm{Cr}^{4+}, \mathrm{Cu}^{2+}$, and $\mathrm{Zn}^{2+}$ from wastewater ${ }^{113}$. The ion exchange mechanism for metal removals can be explained in the following reaction as the ion exchange particle having ion exchanger of $\mathrm{M}^{-} \mathrm{EC}^{+}\left(\mathrm{M}^{-}\right.$is the fixed anion and $\mathrm{EC}^{+}$is the exchange cation; $\mathrm{Na}^{+}$and $\mathrm{H}^{+}$are frequently used as exchange cations) to exchange its cation $\left(\mathrm{EC}^{+}\right)$with the wastewater cation $\left(\mathrm{WC}^{+}\right)^{114}$.

$\mathrm{M}^{-} \mathrm{EC}^{+}+\mathrm{WC}^{+} \Leftrightarrow \mathrm{M}^{-} \mathrm{WC}^{+}+\mathrm{EC}^{+}$

Different types, such as Amberlite ${ }^{115}$ and Diaion CR11 $1^{116}$, were investigated for cations removal. Zeolite has an excellent ion exchange capability owing to its negative charge resulting from $\mathrm{Si}^{4+}$, which resides in the middle of the tetrahedron and undergoes isomorphous replacement with $\mathrm{Al}^{3+}$ cations. MOFs have recently been suggested as good candidates for the ion-exchange removal process $^{117}$. Some reported MOFs used for ion-exchange reactions include AMOF-1 (for $\mathrm{Cd}^{2+}, \mathrm{Pb}^{2+}$, and $\mathrm{Hg}^{2+}$ removal ${ }^{118}$ ), $\mathrm{ZIF}-8$ (for $\mathrm{Cu}^{2+}$ removal $^{119}$ ), and ZIF-67 (for $\mathrm{Cr}^{6+}$ removal ${ }^{120}$ ). Supplementary Table 25 lists some studies that focused on the ion exchange method. Like adsorption, the ion exchange method needs more research on stability and reusability.

\section{PHOTOCATALYTIC-BASED SEPARATION}

The photocatalytic process was reported as a simple process for wastewater treatment that uses light and semiconductors, such as 
Methods of wastewater treatment

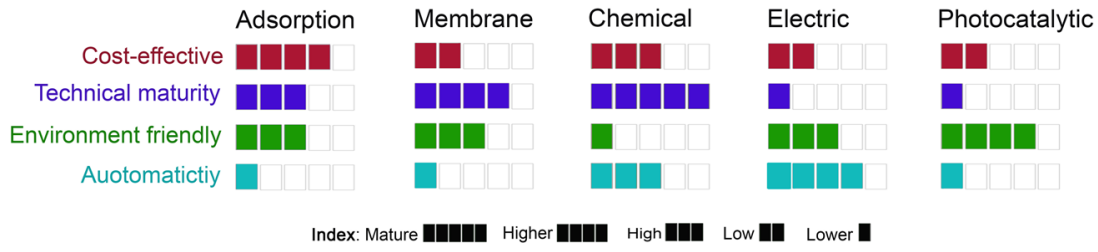

Fig. 9 A general comparison between the typical methods used for heavy metals removal from wastewater. The compared methods are adsorption-, membrane-, chemical-, electric-, and photocatalytic-based in terms of cost-effective, technical maturity, environment friendly, and automaticity, based on the above discussion and the reported studies in the literature ${ }^{51,113,131,133-137}$. The electric- and chemical-based methods are represented here for chemical precipitation and electrochemical processes, respectively ${ }^{133}$.

titanium dioxide $\left(\mathrm{TiO}_{2}\right)^{121}$. Three key steps are taken in this process: charged carrier photogeneration, charged carrier separation and diffusion to the photocatalyst surface, and redox reaction on the photocatalyst surface ${ }^{122}$. The effluents of real soil washing wastewater were treated using an outdoor dual solar photocatalytic process of flat plate collector for the removal of $93.5 \%$ $\mathrm{Cu}^{2+}, 99.6 \% \mathrm{Fe}^{3+}$, and $99.4 \% \mathrm{Zn}^{2+123}$. A simulated ultraviolet (UV)-solar $\mathrm{TiO}_{2}$ photocatalysis has been used for the removal of ethylenediamine- $\mathrm{N}, \mathrm{N}^{\prime}$-disuccinic acid (EDDS), and $\mathrm{Cu}^{2+}$ from wastewater (0.2 mM EDDS and 0.2-1.4 $\left.\mathrm{mM} \mathrm{CuSO}_{4}\right)$ to obtain $100 \%$ conversion efficiency at $24 \%$ mineralization degree ${ }^{124}$. In another study, maximum removal efficiencies of $41 \% \mathrm{Cu}^{2+}, 100 \% \mathrm{Fe}^{3+}$, $100 \% \mathrm{Zn}^{2+}$ and $100 \%$ EDDS were obtained from synthetic soil washing solution $\left(3.6 \times 10^{-1} \mathrm{mM}\right.$ EDDS, $8.0 \times 10^{-2} \mathrm{mM} \mathrm{Cu}^{+2}, 1.0 \times$ $10^{-1} \mathrm{mM} \mathrm{Fe}^{+3}$ and $\left.8.0 \times 10^{-2} \mathrm{mM} \mathrm{Zn}^{+2}\right)^{125}$.

Using visible light irradiation, a synthesized rhodium/antimony co-doped $\mathrm{TiO}_{2}$ nano-rod and titanate nanotube (RS-TONR/TNT) was used to extracts $\mathrm{Pb}^{2+}, \mathrm{Cd}^{2+}, \mathrm{Cu}^{2+}, \mathrm{Zn}^{2+}$, and organic pollutant from wastewater with 70 and $80 \%$ degradation efficiency for dye and Bisphenol $\mathrm{A}$, respectively ${ }^{126}$. The photocatalytic process using $\mathrm{CeO}_{2} / \mathrm{BiOIO}_{3}$ composites with $\mathrm{Ce}^{4+} / \mathrm{Ce}^{3+}$ redox centers was used to attain $86.53 \% \mathrm{Hg}^{2+}$ removal efficiency under visible light absorption and photocatalytic activity ${ }^{127}$. In an aqueous solution containing $\mathrm{As}^{5+}$ and $\mathrm{Cr}^{6+}$ (concentration of $0.10 \mathrm{mg} / \mathrm{L}$ ), a synthesized $3 \mathrm{D}-\mathrm{Fe}_{2} \mathrm{O}_{3}$ was used to achieve nearly $100 \%$ removal rates using solar light irradiation and photocatalytic activity ${ }^{128}$. A fabricated $\mathrm{CH}-\mathrm{GEL} / \mathrm{ZSPNC}$ hybrid nanocomposite ion exchanger achieved $90 \% \mathrm{Ni}^{2+}, 94.9 \% \mathrm{Zn}^{2+}, 95 \% \mathrm{Mg}^{2+}, 100 \% \mathrm{~Pb}^{2+}, 90.3 \%$ $\mathrm{Cd}^{2+}, 88.9 \% \mathrm{Cu}^{2+}$ and $84 \%$ Rhodamine-B (dye) extraction efficiencies using solar light ${ }^{129}$.

A fabricated CS/silver bio-nano-composites (CS/PVDC/Ag) was utilized in photocatalytic oxidation process for $97 \% \mathrm{Cu}^{2+}, 88 \%$ $\mathrm{Pb}^{2+}, 89 \% \mathrm{Cd}^{2+}$ and $77 \%$ dye removal ${ }^{130}$. Although this technology shows the in site generation of reactive radicals, no chemicals used, no sludge production, it has some drawbacks. It is still on a laboratory scale, low throughput, dependent on $\mathrm{pH}$, and inefficient when different metals are present ${ }^{131}$.

\section{REMARKS OF THE TREATMENT METHODS AND FUTURE PERSPECTIVES}

It could be figured out from the discussion above that each method used for metal ions removal is not thoroughly preferred and has its advantages and disadvantages. A general comparison between the typical techniques in terms of economic feasibility, technical maturity, less pollution to the environment, and operation control and automaticity is summarized in Fig. 9.

Among all methods, adsorption is the most considered method in recent years. It showed easy operation, low-cost, and highsorption capacity. Developing eco-friendly and cost-effective adsorbents from wastes is the current research trend. However, disposal of such adsorbents after the adsorption process is a big challenge to avoid environmental risks. Adsorption onto ACs was reported as a feasible method for industrial scale. Adsorption of metal ions from low traces and efficient regeneration processes need additional research. The economic feasibility of industrial applications is also essential.

Membrane methods play a significant role in wastewater treatment and have become a more promising option for wastewater treatment. They are already best-suited for some separation applications such as desalination. Membrane processes are characterized by high metal ions extraction efficiency. However, membrane fouling and biofouling, low recovery for the amount of feed wastewater, process complexity, pretreatment, periodic membrane cleaning, and high cost are some of the shortcomings of this method. The development of novel membrane materials with enhanced thermal and chemical stability for industrial wastewater treatment is needed in the future to attain better anti-fouling properties and enhance membrane selectivity for the target metals. For both adsorption and membrane methods, the automatic operation of industrial plants needs further implementation and improvement.

Chemical-based separations have widely been used for heavy metal removal owing to their simplicity and low cost. Nevertheless, chemicals are consumed for tuning $\mathrm{pH}$ values and enhancing the accumulation of ions. A large-volume sludge is produced that needs further treatment. The electrochemical treatment has the merits of quick treatment, well-controlled, easier sludge removal, and fewer chemicals. However, the high cost of anodes and cathodes, low throughput, high-energy consumption are the main challenges facing this technique. Coupling between different types of electrochemical treatment methods to be driven by renewable energy sources could be promising in addressing this bottleneck. Aerated EC and electrochemical oxidation methods were the best choices to be coupled with other methods due to their ability to eliminate organic and inorganic contaminants from wastewater. The flotation process forms low sludge. So, this method is an excellent candidate to be integrated to build an efficient and cost-effective electrochemical treatment system.

The ion exchange method is similar to the adsorption techniques in which the stability and reusability issues might need more investigation. The photocatalyst method offers simple treatment with no or little chemicals used and no sludge production. However, it is still under research, has low throughput, depends on $\mathrm{pH}$, and is inefficient when different metals are present.

\section{CONCLUSION AND RECOMMENDATIONS}

Selection of the most appropriate technique for heavy ions removal from wastewater depends on many key factors, including the operation cost, initial concentration of the metal ions, environmental impact, $\mathrm{pH}$ values, chemicals added, removal efficiency, and economic feasibility. These methods are classified as adsorption treatments (using different adsorbents, i.e., carbonbased, carbon-composites, minerals, CS, magnetic, biosorbents, and MOFs), membrane treatments (i.e., UF, nanofiltration, 
microfiltration, reverse osmosis, forward osmosis, and electrodialysis), chemical treatments (i.e., chemical precipitation, coagulation-flocculation, and flotation), electric treatments (i.e., electrochemical (reduction, EC, EF, and advanced oxidation) and ion exchange), and photocatalysis.

Adsorption is the most promising method widely investigated in removing heavy metal ions from wastewater due to simple operation, strong applicability, high removal rate, and low cost of reusability. However, this preference depends mainly on selecting low-cost materials, high uptake, and efficient regeneration processes. Comparing to adsorption, the membrane method is technically more mature as it is practical; however, minimizing the separation cost and membrane fouling is still challenging.

The chemical-based methods, especially chemical precipitation, are technically mature and practical. They are also considered cost-effective methods. They depend on the chemical consumed, unlike the electrochemical method that relies on additional factors, including electrodes, electrical energy, and other fixed costs. However, they produce large volume sludge and need sedimentation separation. The electrochemical process is a relatively expensive technology because of the passivation of electrodes and high electrical energy consumption. Furthermore, electric methods, besides the photocatalytic ones, are the least mature technologies. The merit of the photocatalytic method is that no (or less) chemical consumption and less sludge production, making it eco-friendly.

In general, chemical, adsorption, and membrane methods are the most practical method addressed in the literature. It has been noticed that there is a clear knowledge gap in the performance of treatment methods for the removal of heavy metal ions from real wastewater because most studies used synthetic wastewater in which one or few metal types are present. Accordingly, additional research should be conducted using real wastewater for treating different contaminants. More research on introducing costeffective materials and methods for heavy metal removal from wastewater should be carried out. Future studies should also focus on the pilot-scale process. The best techniques to achieve efficient metals recovery with less environmental impact and low cost are still under development and should be considered in future research.

\section{DATA AVAILABILITY}

The authors declare that the data supporting the findings of this study are available within the paper and its supplementary information file.

Received: 18 February 2021; Accepted: 17 June 2021; Published online: 08 July 2021

\section{REFERENCES}

1. El-Sherif, I. Y., Tolani, S., Ofosu, K., Mohamed, O. A. \& Wanekaya, A. K. Polymeric nanofibers for the removal of $\mathrm{Cr}$ (III) from tannery waste water. J. Environ. Manag. 129, 410-413 (2013).

2. Zou, Y. et al. Environmental remediation and application of nanoscale zerovalent iron and its composites for the removal of heavy metal ions: a review. Environ. Sci. Technol. 50, 7290-7304 (2016).

3. Tjandraatmadja, G. et al. Sources of critical contaminants in domestic wastewater: contaminant contribution from household products. (2008).

4. Taseidifar, M., Makavipour, F., Pashley, R. M. \& Rahman, A. F. M. M. Removal of heavy metal ions from water using ion flotation. Environ. Technol. Innov. 8, 182-190 (2017).

5. García-Niño, W. R. \& Pedraza-Chaverrí, J. Protective effect of curcumin against heavy metals-induced liver damage. Food Chem. Toxicol. 69, 182-201 (2014).

6. Borba, C. E., Guirardello, R., Silva, E. A., Veit, M. T. \& Tavares, C. R. G. Removal of nickel(II) ions from aqueous solution by biosorption in a fixed bed column: Experimental and theoretical breakthrough curves. Biochem. Eng. J. 30, 184-191 (2006).
7. Yang, X. et al. Surface functional groups of carbon-based adsorbents and their roles in the removal of heavy metals from aqueous solutions: a critical review. Chem. Eng. J. 366, 608-621 (2019).

8. Karnib, M., Kabbani, A., Holail, H. \& Olama, Z. Heavy metals removal using activated carbon, silica and silica activated carbon composite. Energy Procedia 50, 113-120 (2014)

9. Demiral, I., Samdan, C. \& Demiral, H. Enrichment of the surface functional groups of activated carbon by modification method. Surf. Interfaces 22, 100873 (2021).

10. Krishna Kumar, A. S., Jiang, S. J. \& Tseng, W. L. Effective adsorption of chromium (vi)/Cr(iii) from aqueous solution using ionic liquid functionalized multiwalled carbon nanotubes as a super sorbent. J. Mater. Chem. A 3, 7044-7057 (2015).

11. Duan, C., Ma, T., Wang, J. \& Zhou, Y. Removal of heavy metals from aqueous solution using carbon-based adsorbents: a review. J. Water Process Eng. 37, 101339 (2020).

12. Marciniak, M., Goscianska, J., Frankowski, M. \& Pietrzak, R. Optimal synthesis of oxidized mesoporous carbons for the adsorption of heavy metal ions. J. Mol. Liq. 276, 630-637 (2019).

13. Owalude, S. O. \& Tella, A. C. Removal of hexavalent chromium from aqueous solutions by adsorption on modified groundnut hull. Beni-Suef Univ. J. Basic Appl. Sci. 5, 377-388 (2016).

14. Ngah, W. S. W. \& Fatinathan, S. Adsorption of $\mathrm{Cu}(\mathrm{II})$ ions in aqueous solution using chitosan beads, chitosan-GLA beads and chitosan-alginate beads. Chem. Eng. J. 143, 62-72 (2008).

15. Upadhyay, U., Sreedhar, I., Singh, S. A., Patel, C. M. \& Anitha, K. L. Recent advances in heavy metal removal by chitosan based adsorbents. Carbohydr. Polym. 251, 117000 (2021).

16. Vakili, M. et al. Novel crosslinked chitosan for enhanced adsorption of hexavalent chromium in acidic solution. Chem. Eng. J. 347, 782-790 (2018).

17. Mohammadzadeh Pakdel, P. \& Peighambardoust, S. J. Review on recent progress in chitosan-based hydrogels for wastewater treatment application. Carbohydr. Polym. 201, 264-279 (2018).

18. Refaat Alawady, A., Ali Alshahrani, A., Ali Aouak, T. \& Mohamed Alandis, N. Polysulfone membranes with CNTs/Chitosan biopolymer nanocomposite as selective layer for remarkable heavy metal ions rejection capacity. Chem. Eng. J. 388, 124267 (2020).

19. Kazemi, E., Dadfarnia, S., Haji Shabani, A. M. \& Ranjbar, M. Synthesis, characterization, and application of a Zn (II)-imprinted polymer grafted on graphene oxide/magnetic chitosan nanocomposite for selective extraction of zinc ions from different food samples. Food Chem. 237, 921-928 (2017).

20. Liu, L. et al. Preparation and characterization of chitosan/graphene oxide composites for the adsorption of $\mathrm{Au}(\mathrm{III})$ and Pd(II). Talanta 93, 350-357 (2012).

21. Li, Y., Li, L. \& Yu, J. Applications of zeolites in sustainable. Chem. Chem. $\mathbf{3}$, 928-949 (2017).

22. Zhang, T. et al. Removal of heavy metals and dyes by clay-based adsorbents: from natural clays to 1D and 2D nano-composites. Chem. Eng. J. https://doi.org/ 10.1016/j.cej.2020.127574 (2020).

23. Alshameri, A. et al. Understanding the role of natural clay minerals as effective adsorbents and alternative source of rare earth elements: adsorption operative parameters. Hydrometallurgy 185, 149-161 (2019).

24. Hao, S. et al. Optimal synthesis of amino-functionalized mesoporous silicas for the adsorption of heavy metal ions. Microporous Mesoporous Mater. 236, 250-259 (2016).

25. Li, Z. et al. Disinfection and removal performance for Escherichia coli, toxic heavy metals and arsenic by wood vinegar-modified zeolite. Ecotoxicol. Environ. Saf. 174, 129-136 (2019).

26. Hua, M. et al. Heavy metal removal from water/wastewater by nanosized metal oxides: a review. J. Hazard. Mater. 211-212, 317-331 (2012).

27. Zhou, W. et al. Construction of MoS2 nanoarrays and MoO3 nanobelts: two efficient adsorbents for removal of $\mathrm{Pb}$ (II), $\mathrm{Au}$ (III) and Methylene Blue. J. Environ. Sci. 111, 38-50 (2022).

28. Behbahani, E. S., Dashtian, K. \& Ghaedi, M. Fe3O4-FeMoS4: promise magnetite $\mathrm{LDH}$-based adsorbent for simultaneous removal of $\mathrm{Pb}$ (II), Cd (II), and Cu (II) heavy metal ions. J. Hazard. Mater. https://doi.org/10.1016/j. jhazmat.2020.124560 (2020).

29. Liu, L. et al. Fabrication of novel magnetic core-shell chelating adsorbent for rapid and highly efficient adsorption of heavy metal ions from aqueous solution. J. Mol. Liq. 313, 113593 (2020).

30. Costa, H. P. de S., da Silva, M. G. C. \& Vieira, M. G. A. Biosorption of aluminum ions from aqueous solutions using non-conventional low-cost materials: a review. J. Water Process Eng. 40, 101925 (2021).

31. Abdel Maksoud, M. I. A. et al. Insight on water remediation application using magnetic nanomaterials and biosorbents. Coord. Chem. Rev. 403, 213096 (2020).

32. Ai, T., Jiang, X., Liu, Q., Lv, L. \& Wu, H. Daptomycin adsorption on magnetic ultrafine wood-based biochars from water: kinetics, isotherms, and mechanism studies. Bioresour. Technol. 273, 8-15 (2019). 
33. Gupta, V. K., Ali, I., Saleh, T. A., Siddiqui, M. N. \& Agarwal, S. Chromium removal from water by activated carbon developed from waste rubber tires. Environ. Sci. Pollut. Res. 20, 1261-1268 (2013).

34. Xu, G. R. et al. Metal organic framework (MOF)-based micro/nanoscaled materials for heavy metal ions removal: the cutting-edge study on designs, synthesis, and applications. Coord. Chem. Rev. 427, 213554 (2021).

35. Jamshidifard, S. et al. Incorporation of UiO-66-NH2 MOF into the PAN/chitosan nanofibers for adsorption and membrane filtration of $\mathrm{Pb}(\mathrm{II}), \mathrm{Cd}(\mathrm{II})$ and $\mathrm{Cr}(\mathrm{VI})$ ions from aqueous solutions. J. Hazard. Mater. 368, 10-20 (2019).

36. Zhang, Y. et al. Insight into the efficient co-removal of $\mathrm{Cr}(\mathrm{VI})$ and $\mathrm{Cr}(\mathrm{III})$ by positively charged UiO-66-NH2 decorated ultrafiltration membrane. Chem. Eng. J. 404, 126546 (2021).

37. Wang, C. et al. Development of mercaptosuccinic anchored MOF through onestep preparation to enhance adsorption capacity and selectivity for $\mathrm{Hg}(\mathrm{II})$ and $\mathrm{Pb}(\mathrm{II})$. J. Mol. Liq. 317, 113896 (2020).

38. Alizadeh, B., Ghorbani, M. \& Salehi, M. A. Application of polyrhodanine modified multi-walled carbon nanotubes for high efficiency removal of $\mathrm{Pb}$ (II) from aqueous solution. J. Mol. Liq. 220, 142-149 (2016).

39. Zhang, Y. et al. Highly efficient adsorption of copper ions by a PVP-reduced graphene oxide based on a new adsorptions mechanism. Nano-Micro Lett. $\mathbf{6}$, 80-87 (2014).

40. Rad, L. R. et al. Removal of $\mathrm{Ni} 2+$ and $\mathrm{Cd} 2+$ ions from aqueous solutions using electrospun PVA/zeolite nanofibrous adsorbent. Chem. Eng. J. 256, 119-127 (2014).

41. Shin, K.-Y., Hong, J.-Y. \& Jang, J. Heavy metal ion adsorption behavior in nitrogen-doped magnetic carbon nanoparticles: isotherms and kinetic study. J. Hazard. Mater. 190, 36-44 (2011).

42. Dubey, R., Bajpai, J. \& Bajpai, A. K. Green synthesis of graphene sand composite (GSC) as novel adsorbent for efficient removal of $\mathrm{Cr}(\mathrm{VI})$ ions from aqueous solution. J. Water Process Eng. 5, 83-94 (2015).

43. Hayati, B. et al. Heavy metal adsorption using PAMAM/CNT nanocomposite from aqueous solution in batch and continuous fixed bed systems. Chem. Eng. J. 346 258-270 (2018).

44. Karami, H. Heavy metal removal from water by magnetite nanorods. Chem. Eng. J. 219, 209-216 (2013)

45. Malik, R., Dahiya, S. \& lata, S. An experimental and quantum chemical study of removal of utmostly quantified heavy metals in wastewater using coconut husk: a novel approach to mechanism. Int. J. Biol. Macromol. 98, 139-149 (2017).

46. Alijani, H. \& Shariatinia, Z. Synthesis of high growth rate SWCNTs and their magnetite cobalt sulfide nanohybrid as super-adsorbent for mercury removal. Chem. Eng. Res. Des. 129, 132-149 (2018).

47. Liu, L. et al. Surface charge of mesoporous calcium silicate and its adsorption characteristics for heavy metal ions. Solid State Sci. 99, 106072 (2020).

48. $\mathrm{Yi}, \mathrm{X}$. et al. Graphene oxide encapsulated polyvinyl alcohol/sodium alginate hydrogel microspheres for $\mathrm{Cu}$ (II) and U (VI) removal. Ecotoxicol. Environ. Saf. 158, 309-318 (2018).

49. $\mathrm{Yi}, \mathrm{X}$. et al. Encapsulating $\mathrm{Fe} 3 \mathrm{O} 4$ into calcium alginate coated chitosan hydrochloride hydrogel beads for removal of $\mathrm{Cu}(\mathrm{II})$ and $\mathrm{U}(\mathrm{VI})$ from aqueous solutions. Ecotoxicol. Environ. Saf. 147, 699-707 (2018).

50. Zeng, J. et al. Chitosan functionalized iron nanosheet for enhanced removal of As (III) and Sb (III): Synergistic effect and mechanism. Chem. Eng. J. 122999 (2019).

51. Rahmati, N. O., Pourafshari Chenar, M. \& Azizi Namaghi, H. Recent trends of heavy metal removal from water/wastewater by membrane technologies. J. Ind. Eng. Chem. 76, 17-38 (2019).

52. Rahmati, N. O., Pourafshari Chenar, M. \& Azizi Namaghi, H. Removal of free active chlorine from synthetic wastewater by MEUF process using polyethersulfone/titania nanocomposite membrane. Sep. Purif. Technol. 181, 213-222 (2017).

53. Huang, J. et al. Repeating recovery and reuse of SDS micelles from MEUF retentate containing $\mathrm{Cd} 2+$ by acidification UF. Colloids Surf. A Physicochem. Eng. Asp. 520, 361-368 (2017).

54. Tanhaei, B. et al. Simultaneous removal of aniline and nickel from water by micellar-enhanced ultrafiltration with different molecular weight cut-off membranes. Sep. Purif. Technol. 124, 26-35 (2014).

55. Fu, F. \& Wang, Q. Removal of heavy metal ions from wastewaters: A review. J. Environ. Manag. 92, 407-418 (2011).

56. Paulino, A. T. et al. Novel adsorbent based on silkworm chrysalides for removal of heavy metals from wastewaters. J. Colloid Interface Sci. 301, 479-487 (2006).

57. Oyaro, N., Juddy, O., Murago, E. N. M. \& Gitonga, E. The contents of Pb, Cu, Zn and Cd in meat in Nairobi, Kenya. J. Food, Agric. Environ. 5, 119-121 (2007).

58. Rivas, BernabéL. \& Eduardo Pereira, A. M. Functional water-soluble polymers: polymer-metal ion removal and biocide properties. Polym. Int. 58, 1093-1114 (2009).
59. Huda, N., Nik, B., Nik, M., Mohamed, S. \& Aroua, K. Removal of heavy metal ions from mixed solutions via polymer-enhanced ultrafiltration using starch as a water-soluble biopolymer. Environ. Prog. Sustain. Energy 34, 359-367 (2015).

60. Wang, L. K., Chen, J. P., Hung, Y.-T. \& Shammas, N. K. Membrane and Desalination Technologies. Membrane and Desalination Technologies vol. 13 (2011). Springer.

61. Jamil, T. S., Mansor, E. S., Abdallah, H., Shaban, A. M. \& Souaya, E. R. Novel anti fouling mixed matrix $\mathrm{CeO}_{2} / \mathrm{Ce} \mathrm{O}_{12}$ nanofiltration membranes for heavy metal uptake. J. Environ. Chem. Eng. 6, 3273-3282 (2018).

62. Ozaki, H., Sharma, K. \& Saktaywin, W. Performance of an ultra-low-pressure reverse osmosis membrane (ULPROM) for separating heavy metal: effects of interference parameters. Desalination 144, 287-294 (2002).

63. Samaei, S. M., Gato-Trinidad, S. \& Altaee, A. Performance evaluation of reverse osmosis process in the post-treatment of mining wastewaters: Case study of Costerfield mining operations, Victoria, Australia. J. Water Process Eng. 34, $101116(2020)$

64. He, M. et al. Novel polydopamine/metal organic framework thin film nanocomposite forward osmosis membrane for salt rejection and heavy metal removal. Chem. Eng. J. 389, 124452 (2020).

65. Cui, Y., Ge, Q., Liu, X.-Y. \& Chung, T.-S. Novel forward osmosis process to effectively remove heavy metal ions. J. Memb. Sci. 467, 188-194 (2014).

66. Al-Amshawee, S. et al. Electrodialysis desalination for water and wastewater: a review. Chem. Eng. J. 380, 122231 (2020).

67. Nemati, M., Hosseini, S. M. \& Shabanian, M. Novel electrodialysis cation exchange membrane prepared by 2-acrylamido-2-methylpropane sulfonic acid heavy metal ions removal. J. Hazard. Mater. 337, 90-104 (2017).

68. Gherasim, C. V., Křivčík, J. \& Mikulášek, P. Investigation of batch electrodialysis process for removal of lead ions from aqueous solutions. Chem. Eng. J. 256, 324-334 (2014)

69. Min, K. J., Kim, J. H. \& Park, K. Y. Characteristics of heavy metal separation and determination of limiting current density in a pilot-scale electrodialysis process for plating wastewater treatment. Sci. Total Environ. 757, 143762 (2021).

70. Basha, C. A., Selvi, S. J., Ramasamy, E. \& Chellammal, S. Removal of arsenic and sulphate from the copper smelting industrial effluent. Chem. Eng. J. 141, 89-98 (2008).

71. Santos, P. G., Scherer, C. M., Fisch, A. G. \& Rodrigues, M. A. S. Petrochemical wastewater treatment: water recovery using membrane distillation. J. Clean. Prod. 267, 121985 (2020).

72. Qu, D. et al. Experimental study of arsenic removal by direct contact membrane distillation. J. Hazard. Mater. 163, 874-879 (2009).

73. Zaheri, P., Mohammadi, T., Abolghasemi, H. \& Ghannadi Maraghe, M. Supported liquid membrane incorporated with carbon nanotubes for the extraction of Europium using Cyanex272 as carrier. Chem. Eng. Res. Des. 100, 81-88 (2015).

74. Jean, E., Villemin, D., Hlaibi, M. \& Lebrun, L. Heavy metal ions extraction using new supported liquid membranes containing ionic liquid as carrier. Sep. Purif. Technol. 201, 1-9 (2018).

75. De Los Ríos, A. P. et al. On the selective separation of metal ions from hydrochloride aqueous solution by pertraction through supported ionic liquid membranes. J. Memb. Sci. 444, 469-481 (2013).

76. Ojovan, M. I., Lee, W. E. \& Kalmykov, S. N. in Treatment of Radioactive Wastes. (eds. Ojovan, M. I., Lee, W. E. \& Kalmykov, S. N. B. T.-A. I. to N. W. I. (Third E.) Ch 16, 231-269 (Elsevier, 2019).

77. Yadav, M., Gupta, R. \& Sharma, R. K. in Green and Sustainable Pathways for Wastewater Purification. (ed. Ahuja, S. B. T.-A. in W. P. T.) 355-383 (Elsevier, 2019).

78. Park, J.-H., Choi, G.-J. \& Kim, S.-H. Effects of $\mathrm{pH}$ and slow mixing conditions on heavy metal hydroxide precipitation. J. Korea. Org. Res. Recycl. Assos. 22, 50-56 (2014).

79. Kurniawan, T. A., Chan, G. Y. S., Lo, W.-H. \& Babel, S. Physico-chemical treatment techniques for wastewater laden with heavy metals. Chem. Eng. J. 118, 83-98 (2006).

80. Al-Hemaidi, W. K. Approach in choosing suitable technology for industrial wastewater. J. Civil \& Envir. Eng. 2, 1000123 (2012).

81. Anotai, J., Tontisirin, P. \& Churod, P. Integrated treatment scheme for rubber thread wastewater: sulfide precipitation and biological processes. J. Hazard. Mater. 141, 1-7 (2007).

82. Patterson, J. W., Allen, H. E. \& Scala, J. J. Carbonate precipitation for heavy metals pollutants. J. Water Pollut. Control Federation 49, 2397-2410 (1977).

83. Zueva, S. B. in Waste Electrical and Electronic Equipment Recycling: Aqueous Recovery Methods (eds. Vegliò, F. \& Birloaga, I. B. T.-W. E. and E. E. R.) 213-240 (Woodhead Publishing, 2018).

84. Kremer, M. L. The fenton reaction. Dependence of the rate on pH. J. Phys. Chem A 107, 1734-1741 (2003).

85. Bossmann, S. H. et al. New evidence against hydroxyl radicals as reactive intermediates in the thermal and photochemically enhanced fenton reactions. J. Phys. Chem. A 102, 5542-5550 (1998). 
86. Fu, F., Wang, Q. \& Tang, B. Effective degradation of C.I. Acid Red 73 by advanced Fenton process. J. Hazard. Mater. 174, 17-22 (2010).

87. Wang, S. A Comparative study of Fenton and Fenton-like reaction kinetics in decolourisation of wastewater. Dye. Pigment. 76, 714-720 (2008).

88. Namkung, K. C., Burgess, A. E., Bremner, D. H. \& Staines, H. Advanced Fenton processing of aqueous phenol solutions: a continuous system study including sonication effects. Ultrason. Sonochem. 15, 171-176 (2008).

89. Ibarra-Rodríguez, D., Lizardi-Mendoza, J., López-Maldonado, E. A. \& OropezaGuzmán, M. T. Capacity of 'nopal' pectin as a dual coagulant-flocculant agent for heavy metals removal. Chem. Eng. J. 323, 19-28 (2017).

90. Chang, Q., Zhang, M. \& Wang, J. Removal of Cu2+ and turbidity from wastewater by mercaptoacetyl chitosan. J. Hazard. Mater. 169, 621-625 (2009).

91. Nourani, M., Baghdadi, M., Javan, M. \& Bidhendi, G. N. Production of a biodegradable flocculant from cotton and evaluation of its performance in coagulation-flocculation of kaolin clay suspension: Optimization through response surface methodology (RSM). J. Environ. Chem. Eng. 4, 1996-2003 (2016).

92. Teh, C. Y., Budiman, P. M., Shak, K. P. Y. \& Wu, T. Y. Recent advancement of coagulation-flocculation and its application in wastewater treatment. Ind. Eng. Chem. Res. 55, 4363-4389 (2016).

93. Edzwald, J. K. Dissolved air flotation and me. Water Res. 44, 2077-2106 (2010).

94. Peng, W. et al. An overview on the surfactants used in ion flotation. J. Mol. Liq. 286, 110955 (2019).

95. Hoseinian, F. S., Rezai, B., Kowsari, E., Chinnappan, A. \& Ramakrishna, S. Synthesis and characterization of a novel nanocollector for the removal of nickel ions from synthetic wastewater using ion flotation. Sep. Purif. Technol. 240, 116639 (2020).

96. Salmani, M. H., Davoodi, M., Ehrampoush, M. H., Ghaneian, M. T. \& Fallahzadah, M. H. Removal of cadmium (II) from simulated wastewater by ion flotation technique. Iran. J. Environ. Heal. Sci. Eng. 10, 16 (2013).

97. Mahne, E. J. \& Pinfold, T. A. Precipitate flotation I. Removal of nickel from dilute aqueous solutions and its separation from cobalt. J. Appl. Chem. 18, 52-54 (2007).

98. Pretorius, W. A., Johannes, W. G. \& Lempert, G. G. Electrolytic iron flocculant production with a bipolar electrode in series arrangement. Water SA 17, 133-138 (1991).

99. Yang, X., Liu, L., Tan, W., Qiu, G. \& Liu, F. High-performance Cu2+ adsorption of birnessite using electrochemically controlled redox reactions. J. Hazard. Mater. 354, 107-115 (2018).

100. Jin, W., Fu, Y., Hu, M., Wang, S. \& Liu, Z. Highly efficient SnS-decorated $\mathrm{Bi}_{2} \mathrm{O}_{3}$ nanosheets for simultaneous electrochemical detection and removal of $\mathrm{Cd}(\mathrm{II})$ and $\mathrm{Pb}$ (II). J. Electroanal. Chem. 856, 113744 (2020).

101. Baghban, E., Mehrabani-Zeinabad, A. \& Moheb, A. The effects of operational parameters on the electrochemical removal of cadmium ion from dilute aqueous solutions. Hydrometallurgy 149, 97-105 (2014).

102. Moussa, D. T., El-Naas, M. H., Nasser, M. \& Al-Marri, M. J. A comprehensive review of electrocoagulation for water treatment: potentials and challenges. J. Environ. Manag. 186, 24-41 (2017).

103. Liu, L. et al. High-efficiency As(III) oxidation and electrocoagulation removal using hematite with a charge-discharge technique. Sci. Total Environ. 703, 135678 (2020)

104. Zaied, B. K. et al. A comprehensive review on contaminants removal from pharmaceutical wastewater by electrocoagulation process. Sci.Total Environ. 726, 138095 (2020).

105. Ingelsson, M., Yasri, N. \& Roberts, E. P. L. Electrode passivation, faradaic efficiency, and performance enhancement strategies in electrocoagulation-a review. Water Res. 187, 116433 (2020).

106. Sillanpää, M. \& Shestakova, M. In Electrochemical Water Treatment Methods: Fundamentals, Methods and Full Scale Applications (eds. Martínez-Huitle, C. A., Rodrigo, M. A., \& Scialdone, O.) 47-130 (ScienceDirect, 2017).

107. Chen, X., Chen, G. \& Yue, P. L. Novel electrode system for electroflotation of wastewater. Environ. Sci. Technol. 36, 778-783 (2002)

108. Kolesnikov, V. A., Il'in, V. I. \& Kolesnikov, A. V. Electroflotation in wastewater treatment from oil products, dyes, surfactants, ligands, and biological pollutants: a review. Theor. Found. Chem. Eng. 53, 251-273 (2019).

109. Shammas, N. K., Wang, L. K. \& Hahn, H. H. in Flotation Technology (eds. Lawrence, K. W., Shammas, N. K., Selke, W. A., \& Aulenbach, D. B.) 121-164 (Springer, 2010).

110. Mazumder, A., Chowdhury, Z., Sen, D. \& Bhattacharjee, C. Electric field assisted membrane separation for oily wastewater with a novel and cost-effective electrocoagulation and electroflotation enhanced membrane module (ECEFMM). Chem. Eng. Process. - Process Intensif. 151, (2020).

111. Ammar, H. B., Brahim, M., Ben, Abdelhédi, R. \& Samet, Y. Green electrochemical process for metronidazole degradation at BDD anode in aqueous solutions via direct and indirect oxidation. Sep. Purif. Technol. 157, 9-16 (2016).
112. Martínez-Huitle, C. A. \& Ferro, S. Electrochemical oxidation of organic pollutants for the wastewater treatment: direct and indirect processes. Chem. Soc. Rev. 35 , 1324-1340 (2006).

113. Dạbrowski, A., Hubicki, Z., Podkościelny, P. \& Robens, E. Selective removal of the heavy metal ions from waters and industrial wastewaters by ion-exchange method. Chemosphere 56, 91-106 (2004).

114. Tenório, J. A. S. \& Espinosa, D. C. R. Treatment of chromium plating process effluents with ion exchange resins. Waste Manag. 21, 637-642 (2001).

115. Kang, S.-Y., Lee, J.-U., Moon, S.-H. \& Kim, K.-W. Competitive adsorption characteristics of $\mathrm{CO} 2+, \mathrm{Ni} 2+$, and $\mathrm{Cr} 3+$ by IRN-77 cation exchange resin in synthesized wastewater. Chemosphere 56, 141-147 (2004).

116. Cavaco, S. A., Fernandes, S., Quina, M. M. \& Ferreira, L. M. Removal of chromium from electroplating industry effluents by ion exchange resins. J. Hazard. Mater. 144, 634-638 (2007).

117. Kobielska, P. A., Howarth, A. J., Farha, O. K. \& Nayak, S. Metal-organic frameworks for heavy metal removal from water. Coord. Chem. Rev. 358, 92-107 (2018).

118. Fang, Q.-R. R. et al. Functional mesoporous metal-organic frameworks for the capture of heavy metal ions and size-selective catalysis. Inorg. Chem. 49, 11637-11642 (2010).

119. Zhang, Y. et al. Unveiling the adsorption mechanism of zeolitic imidazolate framework-8 with high efficiency for removal of copper ions from aqueous solutions. Dalt. Trans. 45, 12653-12660 (2016).

120. Li, X., Gao, X., Ai, L. \& Jiang, J. Mechanistic insight into the interaction and adsorption of $\mathrm{Cr}(\mathrm{VI})$ with zeolitic imidazolate framework-67 microcrystals from aqueous solution. Chem. Eng. J. 274, 238-246 (2015).

121. Barakat, M. A. New trends in removing heavy metals from industrial wastewater. Arab. J. Chem. 4, 361-377 (2011).

122. Nasir, A. M. et al. A review on floating nanocomposite photocatalyst: fabrication and applications for wastewater treatment. J. Water Process Eng. 36, 101300 (2020).

123. Onotri, L. et al. Solar photocatalytic processes for treatment of soil washing wastewater. Chem. Eng. J. 318, 10-18 (2017).

124. Satyro, S. et al. Removal of EDDS and copper from waters by $\mathrm{TiO} 2$ photocatalysis under simulated UV-solar conditions. Chem. Eng. J. 251, 257-268 (2014).

125. Satyro, S. et al. Simulated solar photocatalytic processes for the simultaneous removal of EDDS, $\mathrm{Cu}(\mathrm{II}), \mathrm{Fe}(\mathrm{III})$ and $\mathrm{Zn}(\mathrm{II})$ in synthetic and real contaminated soil washing solutions. J. Environ. Chem. Eng. 2, 1969-1979 (2014).

126. Dhandole, L. K. et al. Simultaneous and synergistic effect of heavy metal adsorption on the enhanced photocatalytic performance of a visible-lightdriven RS-TONR/TNT composite. Environ. Res. 180, 108651 (2020).

127. Xiao, Y. et al. $\mathrm{CeO} 2 / \mathrm{BiOlO} 3$ heterojunction with oxygen vacancies and $\mathrm{Ce} 4+/ \mathrm{Ce} 3$ + redox centers synergistically enhanced photocatalytic removal heavy metal. Appl. Surf. Sci. 530, 147116 (2020)

128. Lee, S. C. et al. Hierarchically three-dimensional (3D) nanotubular sea urchinshaped iron oxide and its application in heavy metal removal and solar-induced photocatalytic degradation. J. Hazard. Mater. 354, 283-292 (2018).

129. Kaur, K. \& Jindal, R. Synergistic effect of organic-inorganic hybrid nanocomposite ion exchanger on photocatalytic degradation of Rhodamine-B dye and heavy metal ion removal from industrial effluents. J. Environ. Chem. Eng. 6, 7091-7101 (2018).

130. Al-Sherbini, A. S. A., Ghannam, H. E. A., El-Ghanam, G. M. A., El-Ella, A. A. \& Youssef, A. M. Utilization of chitosan/Ag bionanocomposites as eco-friendly photocatalytic reactor for Bactericidal effect and heavy metals removal. Heliyon 5, e01980 (2019).

131. Crini, G. \& Lichtfouse, E. Advantages and disadvantages of techniques used for wastewater treatment. Environ. Chem. Lett. 17, 145-155 (2019).

132. WHO. Guidelines for drinking-water quality: Fourthedition incorporating the first addendum. Guidelines for Drinking-Water Quality: Fourth Edition Incorporating the First Addendum (2014).

133. Qiu, B. et al. Biochar as a low-cost adsorbent for aqueous heavy metal removal: a review. J. Anal. Appl. Pyrolysis 155, 105081 (2021).

134. Kumar, M., Nandi, M. \& Pakshirajan, K. Recent advances in heavy metal recovery from wastewater by biogenic sulfide precipitation. J. Environ. Manag. 278, 111555 (2021).

135. Martínez-Huitle, C. A. \& Panizza, M. Electrochemical oxidation of organic pollutants for wastewater treatment. Curr. Opin. Electrochem. 11, 62-71 (2018)

136. Hu, K., Xu, D. \& Chen, Y. An assessment of sulfate reducing bacteria on treating sulfate-rich metal-laden wastewater from electroplating plant. J. Hazard. Mater. 393, 122376 (2020).

137. Burakov, A. E. et al. Adsorption of heavy metals on conventional and nanostructured materials for wastewater treatment purposes: a review. Ecotoxicol. Environ. Saf. 148, 702-712 (2018). 


\section{ACKNOWLEDGEMENTS}

The authors would like to thank the Deanship of Research Oversight and Coordination at King Fahd University of Petroleum and Minerals (KFUPM), Dhahran, Saudi Arabia, for supporting this research.

\section{AUTHOR CONTRIBUTIONS}

N.A.A.Q.: Conceptualization, Literature review, Data analysis, Editing, Revision, Writing R.H.M.: Literature review, Data analysis, Editing, Writing. D.U.L.: Literature review, Data analysis, Editing, Writing.

\section{COMPETING INTERESTS}

The authors declare no competing interests.

\section{ADDITIONAL INFORMATION}

Supplementary information The online version contains supplementary material available at https://doi.org/10.1038/s41545-021-00127-0.

Correspondence and requests for materials should be addressed to Naef A. A. Qasem
Reprints and permission information is available at http://www.nature.com/ reprints

Publisher's note Springer Nature remains neutral with regard to jurisdictional claims in published maps and institutional affiliations.

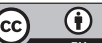

Open Access This article is licensed under a Creative Commons Attribution 4.0 International License, which permits use, sharing, adaptation, distribution and reproduction in any medium or format, as long as you give appropriate credit to the original author(s) and the source, provide a link to the Creative Commons license, and indicate if changes were made. The images or other third party material in this article are included in the article's Creative Commons license, unless indicated otherwise in a credit line to the material. If material is not included in the article's Creative Commons license and your intended use is not permitted by statutory regulation or exceeds the permitted use, you will need to obtain permission directly from the copyright holder. To view a copy of this license, visit http://creativecommons. org/licenses/by/4.0/.

(c) The Author(s) 2021, corrected publication 2021 